\title{
Determining Robust Impacts of Land-Use-Induced Land Cover Changes on Surface Climate over North America and Eurasia: Results from the First Set of LUCID Experiments
}

\author{
Nathalie de Noblet-Ducoudré,* Juan-Pablo Boisier, ${ }^{*}$ Andy Pitman, ${ }^{+}$G. B. Bonan, ${ }^{*}$

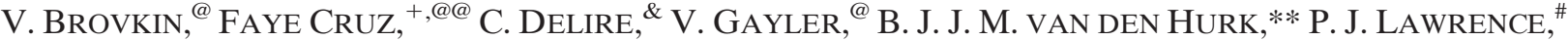 \\ M. K. van Der Molen, ${ }^{* *}$ C. MÜller, ${ }^{++}$C. H. Reick,${ }^{@}$ B. J. Strengers, ${ }^{\# \#}$ AND A. Voldoire ${ }^{\&}$ \\ * Laboratoire des Sciences du Climat et de l'Environnement, Gif-sur-Yvette, France \\ ${ }^{+}$Centre of Excellence for Climate System Science, University of New South Wales, Sydney, New South Wales, Australia \\ \# National Center for Atmospheric Research, Boulder, Colorado \\ @ Max Planck Institute for Meteorology, Hamburg, Germany \\ \& Groupe d'Étude de l'Atmosphère Météorologique, Toulouse, France \\ ** Royal Netherlands Meteorological Institute, De Bilt, Netherlands \\ ${ }^{+}$Earth System Analysis, Potsdam Institute for Climate Impact Research, Potsdam, Germany \\ \#\# PBL Netherlands Environmental Assessment Agency, Bilthoven, Netherlands
}

(Manuscript received 17 June 2011, in final form 26 October 2011)

\begin{abstract}
The project Land-Use and Climate, Identification of Robust Impacts (LUCID) was conceived to address the robustness of biogeophysical impacts of historical land use-land cover change (LULCC). LUCID used seven atmosphere-land models with a common experimental design to explore those impacts of LULCC that are robust and consistent across the climate models. The biogeophysical impacts of LULCC were also compared to the impact of elevated greenhouse gases and resulting changes in sea surface temperatures and sea ice extent (CO2SST). Focusing the analysis on Eurasia and North America, this study shows that for a number of variables LULCC has an impact of similar magnitude but of an opposite sign, to increased greenhouse gases and warmer oceans. However, the variability among the individual models' response to LULCC is larger than that found from the increase in CO2SST. The results of the study show that although the dispersion among the models' response to LULCC is large, there are a number of robust common features shared by all models: the amount of available energy used for turbulent fluxes is consistent between the models and the changes in response to LULCC depend almost linearly on the amount of trees removed. However, less encouraging is the conclusion that there is no consistency among the various models regarding how LULCC affects the partitioning of available energy between latent and sensible heat fluxes at a specific time. The results therefore highlight the urgent need to evaluate land surface models more thoroughly, particularly how they respond to a perturbation in addition to how they simulate an observed average state.
\end{abstract}

\section{Introduction}

Land use-land cover change (LULCC) via deforestation, or via conversion of natural grasslands, occurs

@@ Current affiliation: Manila Observatory, Quezon City, Philippines.

Corresponding author address: Nathalie de Noblet-Ducoudré, Laboratoire des Sciences du Climat et de l'Environnement, Bâtiment 712, Orme des Merisiers, Point Courrier 132, F-91191 Gif-sur-Yvette CEDEX, France.

E-mail: nathalie.de-noblet@lsce.ipsl.fr principally for urbanization and agriculture. It is a process that probably began with human's systematic use of fire $\sim 400000 \mathrm{yr}$ ago (Williams 2003). There is no doubt that LULCC has been geographically extensive (Defries et al. 1995; Ramankutty and Foley 1999; Klein Goldewijk 2001; Hurtt et al. 2006; Pongratz et al. 2008; Klein Goldewijk et al. 2011; Kaplan et al. 2011). LULCC affects the nature of the land surface in ways strongly determined by the type of change. The impact of removing forests for agriculture depends on the spatial scale of the change. It also depends on the type of natural vegetation removed, since a coniferous forest interacts with the atmosphere differently than a deciduous 
forest, and both differ significantly from a native grassland or savanna system. The impact of LULCC also depends on the type of crops implemented, whether the crops are irrigated, and whether the croplands revert back to something similar to the original vegetation over time or are maintained as crops or are transformed to urban landscapes. Large-scale LULCC affects the mean regional climate (e.g., Bonan 1997; Gallo et al. 1999; Zhou et al. 2004; Oleson et al. 2004; Hale et al. 2006; Lobell and Bonfils 2008; Mahmood et al. 2008; Fall et al. 2010) but also the likelihood of extremes (Zhao and Pitman 2002; Deo et al. 2009; Teuling et al. 2010), carbon and other trace gas emissions (Denman et al. 2007), fluxes of biologically active volatile organic compounds (Arneth et al. 2010), and the direct heating of the atmosphere through anthropogenic heat input (McCarthy et al. 2010). LULCC has also had a substantial biogeochemical effect on global climate through emission of $\mathrm{CO}_{2}$ and other greenhouse gases (GHGs), such as $\mathrm{CH}_{4}$ and $\mathrm{N}_{2} \mathrm{O}$ (Denman et al. 2007), although such impacts and exchanges are not within the scope of this paper.

The biogeochemical effect of historical LULCC on climate is reasonably well established. LULCC releases $\mathrm{CO}_{2}$, and therefore increases radiative forcing, although the magnitude of this increase still requires accurate quantification. In contrast, the impact of the biogeophysical effects of LULCC is more uncertain. While the land surface modeling community would basically agree that LULCC is a significant driver of climate through physical effects, there is no consensus on what this statement means. The community would agree that LULCC affects the albedo and through the albedo the energy to drive the surface energy balance. LULCC also affects how that energy is partitioned into sensible and latent heat fluxes, the turbulent energy fluxes that transfer water and heat into the atmosphere. There is a general consensus that provided LULCC is spatially coherent and on a spatial scale that is large enough, this would change the regional-scale climate significantly. However, the community could not define the scale of LULCC required to be "large enough," how large the resulting change in the regional climate might be expected to be, or how the nature of the existing climate over a region might suppress or amplify the initial impacts of LULCC. Most contentious is the unresolved question of whether an LULCC-induced regional climate change teleconnects to trigger significant remote (in space) changes in climate. Some climate modeling evidence suggests that it can (Henderson-Sellers et al. 1993; Zhang et al. 1996; Gedney and Valdes 2000; Werth and Avissar 2002, 2005) and other climate modeling evidence suggests it cannot (Findell et al. 2007, 2009; Pitman et al. 2009), and this is not a problem easily resolved using observational evidence.
Another complication arises from the type of climate model used in the LULCC experiments. Experiments with prescribed sea surface temperatures (SSTs) and sea ice cover could underestimate the global effects of LULCC because air temperature over ocean, which covers $71 \%$ of the planet, is constrained to the observed state.

The global-scale impact of historical LULCC on radiative forcing through land surface albedo changes estimated as $-0.2 \pm 0.2 \mathrm{~W} \mathrm{~m}^{-2}$ is small relative to the $\mathrm{CO}_{2}$ radiative forcing of $1.66 \pm 0.17 \mathrm{~W} \mathrm{~m}^{-2}$ (Forster et al. 2007). However, this does not imply LULCC has no climatic impact, as Pielke et al. (2002) and Davin et al. (2007) have argued. A globally integrated measure of the impact of a forcing is important where a forcing has a global signature. Even if most experiments seem to show that LULCC has a negligible global signature, intense LULCC - where it has transformed large regions of the earth's surface-is spatially organized into distinct regions (Fig. 1). These include (but are not restricted to) North America, Europe, India, China, Russia, Japan, and Indonesia (all account for about $64 \%$ of all arable land on about $50 \%$ of the total land-where $60 \%$ of the global population lives ${ }^{1}$ ). So, the appropriate question is not whether LULCC has a globally averaged significant impact, rather it is whether LULCC has an impact on regions that have undergone intensive LULCC that is worth accounting for when exploring the impact of other human forcings on regional climate.

To begin to systematically address this question, the project Land-Use and Climate, Identification of Robust Impacts (LUCID) was conceived under the auspices of the International Geosphere-Biosphere Programme (IGBP)-Integrated Land Ecosystem-Atmosphere Processes Study (iLEAPS) and the Global Energy and Water Cycle Experiment-Global Land Atmosphere System Study (GEWEX-GLASS). The goal of LUCID is to determine the scale of impact of historical LULCC at the regional and global scales. A key objective is to determine those impacts that are real and robust both above the level of natural variability in each model and common across the set of seven models used in the project (see section 2).

The preliminary global-scale results from LUCID were presented by Pitman et al. (2009), who mainly focused on the Northern Hemisphere summer season. The key result was a statistically significant impact of LULCC on the simulated latent heat flux and air temperature over the regions where LULCC was changed. However, the direction of summer temperature change was inconsistent

\footnotetext{
${ }^{1}$ Percentages include all land areas except Greenland and Antarctica.
} 


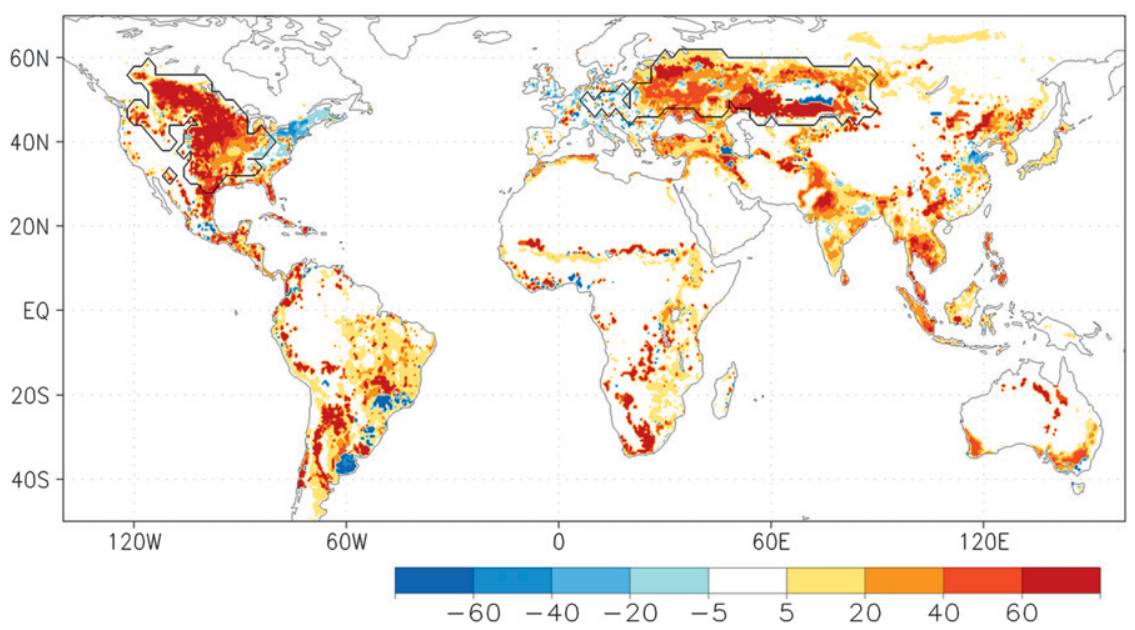

FIG. 1. Changes in the extent covered with crops and pasture between PD and PI times. Yellow and red are used when the extent of anthropogenic areas have increased since PI times, while blue refers to abandoned lands. The two contours that are drawn on the map highlight the regions that will further be used for specific analysis (North America and Eurasia).

among the models, which undermines our confidence in the robustness of this result. In the case of rainfall, Seneviratne et al. (2010) noted that results from LULCC were less convincing. Four of the coupled atmosphereland models used in LUCID show a strongly significant impact on rainfall over regions of LULCC, while three models do not show impacts above the level expected by chance. Therefore, in terms of the results from LUCID, the model results do not simulate a consistent LULCC signal in terms of regional rainfall. Pitman et al. (2009) also failed to identify statistically significant impacts of LULCC remote from the actual LULCC for latent heat flux, temperature, or rainfall. Note that since LUCID did not use climate models with coupled oceans, this does not resolve the question of whether these teleconnections exist, as the coupled ocean can amplify or damp an initial regional perturbation (Davin and de Noblet-Ducoudré 2010).

A critical result from LUCID was the disagreement between the models in their response to LULCC in the simulation of summer temperature and latent heat flux change. Pitman et al. (2009) did not explore the reasons behind these differences. The goal of this paper is to provide a detailed examination of why the land surface models (LSMs) diverge in their response to LULCC and to provide advice on how to better approach realistic responses of climate models to such perturbations in the future. This paper highlights in detail where the models agree and where they disagree, and it explores the reasons for the disagreement.

Section 2 summarizes the main features of the atmosphere and land surface models used, describes the experimental protocol, the imposed vegetation changes, and the way they were implemented in individual LSMs. Section 3 compares the climatic impacts of LULCC to those resulting from the changes in sea surface temperatures, sea ice extent, and increased greenhouse gases. Section 4 discusses the resulting changes in land surface properties in each individual model, as well as their simulated impacts on fluxes and surface temperature. Section 5 focuses on the way the various models partition the available surface radiative energy into latent and sensible heat fluxes, and on how this partitioning is modified when the land cover distribution is changed. The results are discussed and summarized in section 6 .

\section{Models, experimental design, and resulting vegetation changes}

\section{a. Models description}

Seven coupled atmosphere-LSMs have been used to carry out a common set of simulations using the same experimental design. The models and their references are listed in Table 1.

\section{b. Experimental design}

All seven models undertook two sets of two simulations (Table 2), spanning a matrix of present-day (PD) and preindustrial (PI) GHG concentrations-SSTs and present-day and preindustrial land cover. In these experiments the models are forced with two different vegetation distributions (representative of 1870 or 1992). Each model carried out at least five independent simulations for each experiment to increase the capacity to determine those changes that were robust from those that reflected internal model variability. 
TABLE 1. List of climate (or atmosphere only) models and associated LSMs used in the first LUCID set of experiments.

\begin{tabular}{|c|c|c|c|c|c|c|c|}
\hline $\begin{array}{l}\text { Name of } \\
\text { climate or } \\
\text { atmospheric } \\
\text { models } \\
\text { (reference) }\end{array}$ & $\begin{array}{l}\text { EC-EARTH } \\
\text { (www.ecmwf.int/ } \\
\text { research/ifsdocs/ } \\
\text { CY31r1/) }\end{array}$ & $\begin{array}{l}\text { SPEEDY } \\
\quad \text { (Strengers } \\
\text { et al. 2010) }\end{array}$ & $\begin{array}{l}\text { IPSL } \\
\qquad(\text { Marti } \\
\text { et al. 2010) }\end{array}$ & $\begin{array}{l}\text { ARPEGE } \\
\text { (Salas-Mélia } \\
\text { et al. 2005) }\end{array}$ & $\begin{array}{l}\text { CCAM } \\
\text { (McGregor } \\
\text { and Dix 2008) }\end{array}$ & $\begin{array}{l}\text { CCSM } \\
\text { (Collins } \\
\text { et al. 2006) }\end{array}$ & $\begin{array}{l}\text { ECHAM5 } \\
\text { (Roeckner } \\
\text { et al. 2006) }\end{array}$ \\
\hline $\begin{array}{l}\text { Name of land } \\
\text { surface model } \\
\text { (reference) }\end{array}$ & $\begin{array}{l}\text { TESSEL } \\
\text { (Van den Hurk } \\
\text { et al. 2000) }\end{array}$ & $\begin{array}{l}\text { LPJmL } \\
\qquad \text { (Bondeau } \\
\text { et al. 2007) }\end{array}$ & $\begin{array}{l}\text { ORCHIDEE } \\
\text { (Krinner } \\
\text { et al. 2005) }\end{array}$ & $\begin{array}{l}\text { ISBA } \\
\quad(\text { Voldoire 2006) }\end{array}$ & $\begin{array}{l}\text { CABLE } \\
\text { (Wang } \\
\text { et al. 2007; } \\
\text { Abramowitz } \\
\text { et al. 2008) }\end{array}$ & $\begin{array}{l}\text { CLM } \\
\qquad \text { (Oleson } \\
\text { et al. 2008) }\end{array}$ & $\begin{array}{l}\text { JSBACH } \\
\text { (Raddatz } \\
\text { et al. 2007) }\end{array}$ \\
\hline
\end{tabular}

From these simulations we constructed responses to LULCC by averaging the results for land cover change experiments under both present-day and preindustrial GHG concentrations/SSTs [i.e., 0.5(PD - PDv + PIv $\mathrm{PI})$ ]; values computed in this way are termed LULCC in the following. Similarly, the average response to GHG and SST changes is evaluated as 0.5(PD - PIv + PDv $\mathrm{PI}$ ) and labeled "CO2SST" (the combined CO2 and SST impacts) in the following. Results from all individual members of every participating model have been averaged in all the results presented below.

Both SSTs and sea ice extent were prescribed to vary interannually and seasonally using the Climate of the Twentieth Century Project specifications [see Met Office Hadley Centre Sea Ice and Sea Surface Temperature version 1.1 (HadISST1.1) at ftp://www.iges.org/pub/ kinter/c20c/HadISST/]. For the vegetation distribution, each model was provided the same distribution of crop and pasture (Fig. 1), at a resolution of $0.5^{\circ} \times 0.5^{\circ}$. These were constructed by Ramankutty and Foley (1999) and combined with pasture area from Klein Goldewijk (2001). The fields are similar to the ones that are now being used for the Intergovernmental Panel on Climate Change (IPCC) Coupled Model Intercomparison Project phase 5 (CMIP5) historical simulations (Hurtt et al. 2011).

\section{c. Resulting vegetation changes}

The datasets provided to each modeling group did not specify the distribution of natural vegetation (land cover types that are neither crops nor pasture). The distribution of natural vegetation had to be obtained from the datasets currently used by each LSM from their "background" land cover map (BLCm) or from prognostic simulations of vegetation distribution. This was unavoidable, as climate models and their LSMs are commonly developed together with an assumed natural vegetation map. It is simply not feasible to require all modeling groups to use a common natural vegetation map, since it would require a restructuring of the LSM and a full-scale reevaluation of the coupled model.

As an implication, each LSM therefore integrated the crops and pasture distributions provided for both periods into its own land cover map. This has resulted in rather different land cover distributions (Fig. 2a) for

TABLE 2. Description of simulations performed by each coupled atmosphere-LSM.

\begin{tabular}{|c|c|c|c|c|c|}
\hline $\begin{array}{l}\text { Experiment } \\
\text { name }\end{array}$ & Description of the experiment & $\mathrm{CO}_{2}(\mathrm{ppm})$ & Aerosols & $\begin{array}{c}\text { Year of } \\
\text { vegetation map }\end{array}$ & SSTs \\
\hline PI & $\begin{array}{l}\text { PI simulation, with } \mathrm{CO}_{2}, \mathrm{GHGs} \text {, aerosols, } \\
\text { land cover map and SSTs being prescribed } \\
\text { at their preindustrial values }\end{array}$ & 280 & Preindustrial & 1870 & Prescribed 1870-1900 \\
\hline PD & $\begin{array}{l}\text { PD simulation, with PD } \mathrm{CO}_{2} \text {, land cover } \\
\text { map, SSTs, and sea ice extent; other GHGs } \\
\text { have been added to the } \mathrm{CO}_{2} \text { concentration } \\
\text { as } \mathrm{CO}_{2} \text { equivalent,* while aerosols have been } \\
\text { kept to their PI values. }\end{array}$ & 375 & Preindustrial* & 1992 & Prescribed 1972-2002 \\
\hline PIv & $\begin{array}{l}\text { Preindustrial simulation with } \mathrm{CO}_{2} \text {, GHGs, } \\
\text { aerosols, and SSTs being prescribed at their } \\
\text { PI value BUT with PD land cover map }\end{array}$ & 280 & Preindustrial & 1992 & Prescribed 1870-1900 \\
\hline PDv & $\begin{array}{l}\text { PD simulation, with PD } \mathrm{CO}_{2} \text {, SSTs, and sea } \\
\text { ice extent; other GHGs have been added to } \\
\text { the } \mathrm{CO}_{2} \text { concentration as } \mathrm{CO}_{2} \text { equivalent,* } \\
\text { while aerosols have been kept to their } \\
\text { PI values; but land cover map is PI. }\end{array}$ & 375 & Preindustrial* & 1870 & Prescribed 1972-2002 \\
\hline
\end{tabular}

\footnotetext{
* Except in EC-EARTH, where those were changed proportionally to $\mathrm{CO}_{2}$ changes.
} 
a. VEGETATION FRACTION IN 1870
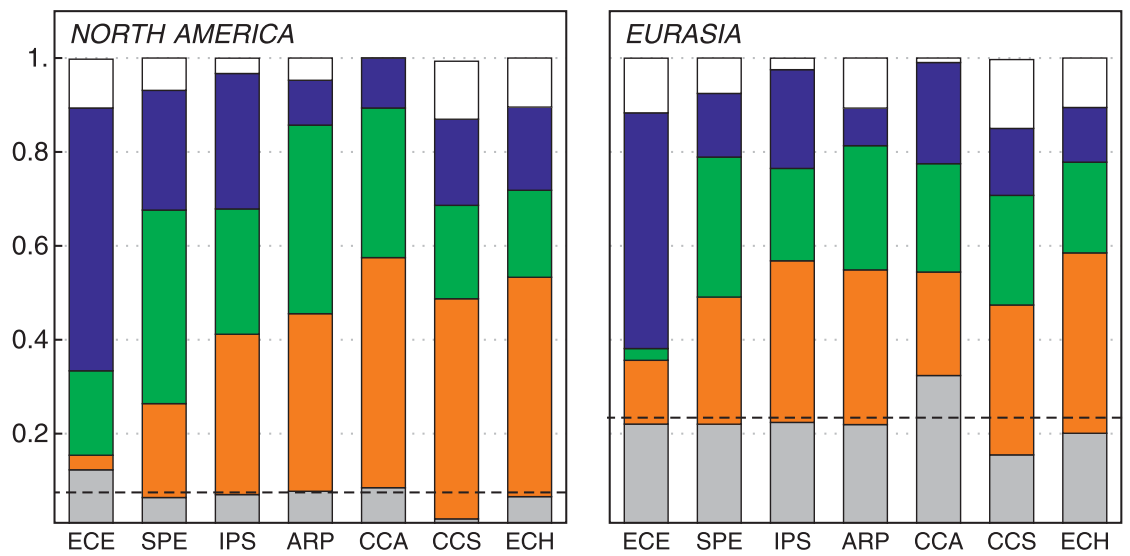

b. FRACTION DIFFERENCE (1992-1870)
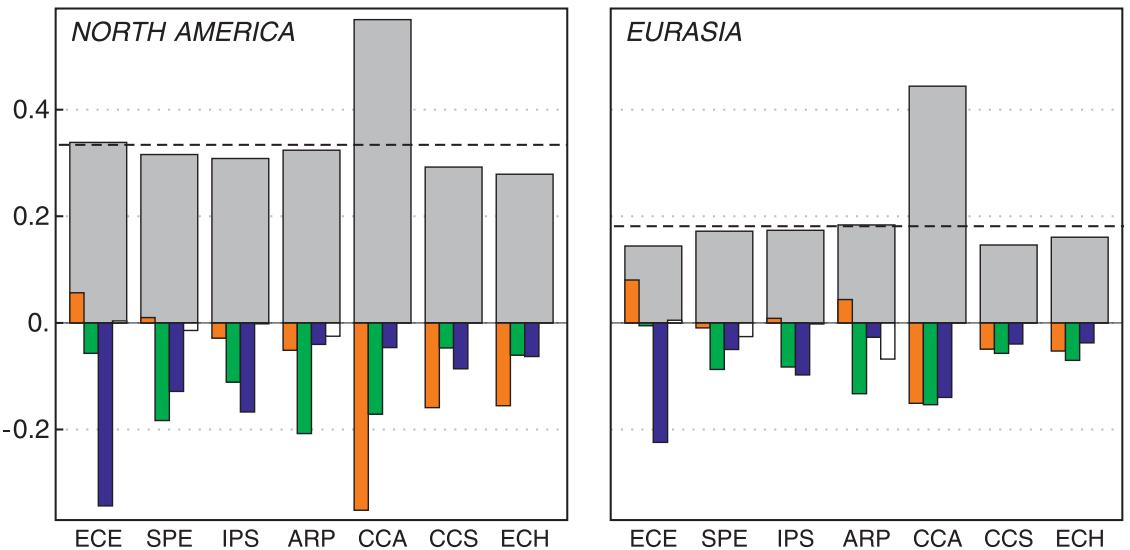

FIG. 2. (a) The 1870 extent (in fraction of total area) covered by crops (gray), grassland types (orange), evergreen trees (green), deciduous trees (blue), and desert (white) for all seven models and two different geographical locations (North America and Eurasia; located in Fig. 1). (b) Differences (in fraction of total area) in each of those vegetation types between PD and PI times. The dashed black line on both graphs shows the fractional coverage by crops that have been provided.

several reasons: 1) differences in the way land information is represented in different models; 2) different modeling groups use different sources of information to describe present-day and potential vegetation; and 3) various groups have developed different strategies to implement LULCC in their model (Table 3). Presentday crop fraction in North America, for example, varies from $35 \%$ in the Community Climate System Model (CCSM)-Community Land Model (CLM) to more than $60 \%$ in the Conformal-Cubic Atmospheric Model (CCAM), while the extent of deciduous forests varies from about $5 \%$ in both the Action de Recherche Petite Echelle Grande Echelle (ARPEGE)-Interactions between Soil, Biosphere, and Atmosphere (ISBA) and CCAMCommonwealth Scientific and Industrial Research Organisation Atmosphere Biosphere Land Exchange (CABLE) to more than $30 \%$ in the earth system model based on European Centre for Medium-Range Weather Forecasts (ECMWF) modeling systems (EC-EARTH)Tiled ECMWF Scheme of Surface Exchanges over Land (TESSEL). Moreover, although the areas covered with crops increase in all models from preindustrial times to the present (Fig. 2b), this increase varies from about $30 \%$ in CCSM-CLM, which is less than the $35 \%$ originally prescribed, to about $55 \%$ in CCAM-CABLE.

The models therefore all experience temperate deforestation but at varying degrees. For example, for North America, temperate deforestation ranges from $12 \%$ in ECHAM5-Jena Scheme for Biosphere-Atmosphere Coupling in Hamburg (JSBACH) to $40 \%$ in ECEARTH-TESSEL (Table 4). In EC-EARTH-TESSEL, Simplified Parameterizations, Primitive-Equation Dynamics (SPEEDY)-Lund-Potsdam-Jena Model for managed land (LPJmL), ARPEGE-ISBA, and L'Institut 


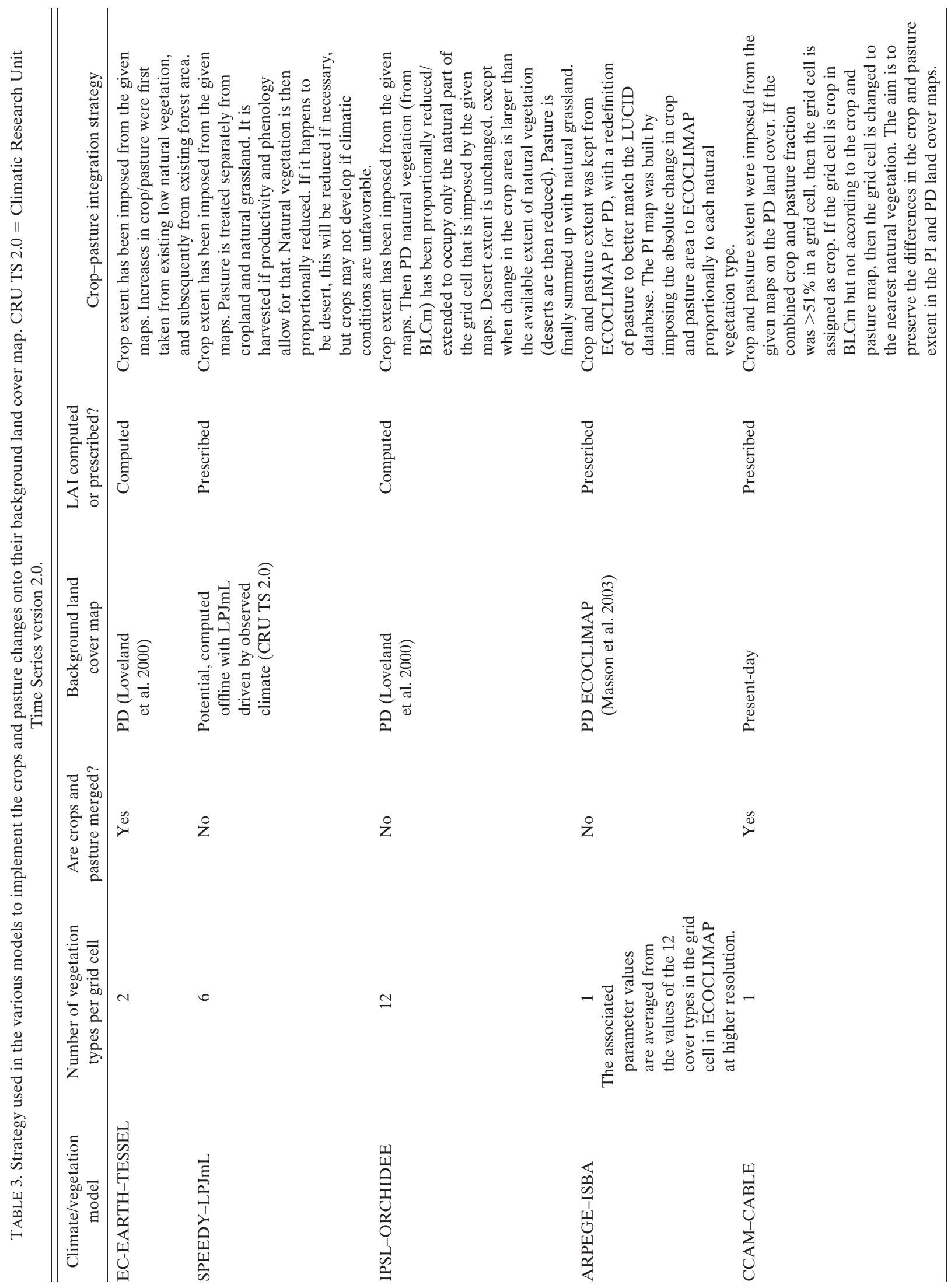


Pierre-Simon Laplace (IPSL)-Organizing Carbon and Hydrology in Dynamic Ecosystems (ORCHIDEE), crops have expanded predominantly at the expense of forests, while in CCAM-CABLE, CCSM-CLM, and ECHAM5-JSBACH, the reduction in herbaceous areas is as large or even larger than the reduction in forests.

For the LUCID experiments, five out of seven models have chosen to proportionally reduce/extend all natural vegetation types on the part of the grid cell that is not occupied by crops and/or pasture, while the remaining two have first reduced the grassland area and then forests. Other differences between the resulting maps come from 1) the number of vegetation types accounted for per grid cell and 2) the BLCm. Regarding the first point, CCAMCABLE, for example, only considers the dominant vegetation type per grid cell. If one type exceeds $51 \%$, then it is set to occupy the whole grid cell. This is why the increase in crop area is much larger in this model than in all others. CCAM-CABLE, moreover, groups both pasture and crops into a single vegetation type and both increase from preindustrial times to present day. The extent of herbaceous types decreases in most other models between the two periods, mainly because natural grassland and pasture are most often grouped within one vegetation type. Since natural grassland is severely reduced to allow for the growth of crops, the total grassland area is decreased. As with the choice of whether to grow crops at the expense of forests or herbaceous plants, there is no known "right" choice in the number of vegetation types per grid cell and therefore there is no right choice in how to implement LULCC in a climate model. However, our findings of large differences in the deforestation rate, for example, suggest that we should, collectively, focus on appropriate strategies to implement LULCC in our models. The remaining differences between the resulting maps come from the various configurations of the BLCm among the modeling groups. Various examples exist, including the following:

1) The LSM uses a potential vegetation map, that is, one that only includes natural vegetation types. The crop and pasture extent will therefore, for each individual year, replace some or all natural types (e.g., CCSMCLM, ECHAM5-JSBACH).

2) The LSM uses an observed present-day land cover map that includes both natural and anthropogenic vegetation types. Reconstructing the historical land cover map means deciding which natural vegetation types, crops and pasture would be replaced or deciding what types existed prior to the current distribution of anthropogenic vegetation. Moreover, the distribution of crops and pasture in the BLCm may be different from the present-day distribution provided 
TABLE 4. Forest extent $\left(\mathrm{km}^{2}\right.$; numbers in parenthesis represent the fractional area covered by forests) at both PI time and PD, together with changes in the forested areas $\left(\mathrm{km}^{2}\right.$ and \%) between those two time slices. All models are shown for both geographical regions.

\begin{tabular}{|c|c|c|c|c|c|c|}
\hline \multirow[b]{3}{*}{ Climate/vegetation model } & \multicolumn{6}{|c|}{ Forest area $-10^{6} \mathrm{~km}^{2}(\%$ of covered area $)$} \\
\hline & \multicolumn{3}{|c|}{ North America } & \multicolumn{3}{|c|}{ Eurasia } \\
\hline & 1870 & 1992 & Change & 1870 & 1992 & Change \\
\hline EC-EARTH-TESSEL & $3.36(74)$ & $1.54(34)$ & $1.82(40)$ & $3.14(31)$ & $1.77(30)$ & $1.37(23)$ \\
\hline SPEEDY-LPJmL & $3.04(67)$ & $1.62(36)$ & $1.42(31)$ & $2.58(43)$ & $1.77(30)$ & $0.82(14)$ \\
\hline IPSL-ORCHIDEE & $2.53(56)$ & $1.26(28)$ & $1.27(28)$ & $2.42(41)$ & $1.35(23)$ & $1.07(18)$ \\
\hline ARPEGE-ISBA & $2.26(50)$ & $1.13(25)$ & $1.13(25)$ & $2.05(34)$ & $1.1(18)$ & $0.95(16)$ \\
\hline CCAM-CABLE & $1.93(43)$ & $0.94(21)$ & $0.99(22)$ & $2.66(45)$ & $0.91(15)$ & $1.75(29)$ \\
\hline CCSM-CLM & $1.74(38)$ & $1.13(25)$ & $0.61(13)$ & $2.24(38)$ & $1.66(28)$ & $0.58(10)$ \\
\hline ECHAM5-JSBACH & $1.65(36)$ & $1.09(24)$ & $0.56(12)$ & $1.84(31)$ & $1.2(24)$ & $0.64(11)$ \\
\hline
\end{tabular}

(e.g., IPSL-ORCHIDEE, EC-EARTH-TESSEL, ARPEGE-ISBA, and CCAM-CABLE).

3) The natural distribution of vegetation is computed dynamically by a dynamic global vegetation model (DGVM) included in the climate model. The fraction of natural vegetation with internally computed vegetation composition is reduced in each grid cell to allow for simulating agricultural land (cropland and/ or pastures) in the remainder of the grid cell (e.g., SPEEDY-LPJmL).

We emphasize that the way each modeling group has implemented LULCC is reasonable at this time because the land surface modeling community has not recognized before how many ways there are to implement LULCC, and the required research has not yet been done to establish a preferred methodology. However, while each approach is reasonable, they are different and those differences inevitably have an impact on how LULCC affects the near-surface climate.

\section{How does the models' response to the LULCC signal compare to the response to other changes?}

The four sets of simulations described in section $2 \mathrm{~b}$ allow a comparison of the sensitivity of models to both LULCC and the combined changes in atmospheric greenhouse gases, and CO2SST. To do this, we use the framework of the surface energy balance equation that is implemented in all LSMs. In the absence of snow and on longer time scales, the basic form of this equation is

$$
Q_{S}(1-\alpha)+Q_{\mathrm{Ld}}-Q_{\mathrm{Lu}}=Q_{H}+Q_{E}+Q_{G}
$$

where all fluxes are in watts per square meter, $Q_{S}$ is the shortwave radiation incident at the land surface, $\alpha$ is the surface albedo, $Q_{\mathrm{Ld}}$ is the downwelling infrared radiation, $Q_{\mathrm{Lu}}$ is upwelling infrared radiation, $Q_{H}$ is the sensible heat flux, $Q_{E}$ is the latent heat flux, and $Q_{G}$ is the flux of heat being transmitted to deeper soil layers. The left-hand side of this equation is also known as net radiation. In our analysis we use available energy $\left(Q_{A}\right.$; and not net radiation), defined as

$$
Q_{A}=Q_{S}(1-\alpha)+Q_{\mathrm{Ld}}
$$

Our choice for not including $Q_{\mathrm{Lu}}$ in the available energy (as is more traditionally done) is because we wish to separate $Q_{A}$ into turbulent fluxes on the one hand and long-wave cooling on the other.

We also define the total amount of energy exchanged as a turbulent energy flux $\left(Q_{T}\right)$ as

$$
Q_{T}=Q_{H}+Q_{E}
$$

The responses of $Q_{A}$ and ambient air temperature to both sets of changes are displayed in Fig. 3 for North America and Eurasia for all seasons, while the changes in the terrestrial water budget are displayed in Fig. 4.

\section{a. Changes in energy budget and surface temperature}

Changes in CO2SST lead to an increase in $Q_{A}$ at the surface [typically $3-5 \mathrm{~W} \mathrm{~m}^{-2}$, with larger values during summertime when incoming radiation is maximum (Figs. 3a,b)]. This increase is caused mainly by increased incoming infrared radiation $\left(Q_{\mathrm{Ld}}\right)$ associated with the higher atmospheric $\mathrm{CO}_{2}$. This increased $Q_{A}$ is associated with a surface warming of $0.61 \pm 0.2^{\circ} \mathrm{C}$ in North America and $0.63 \pm 0.27^{\circ} \mathrm{C}$ in Eurasia (Figs. $3 \mathrm{c}, \mathrm{d}$ ), over all seasons with slightly larger values during summertime. In contrast, LULCC, which reflects either deforestation or-at a minimum-shortening of the growing season (when crops replace grasses), results in decreased $Q_{A}$ by a few watts per square meter over land. There is a small seasonal cycle in the reduction in $Q_{A}$, particularly over Eurasia, where larger reductions are simulated due to the combined effects of snow-increased albedo and larger incoming solar radiation in summer compared to winter. The response to increased surface albedo will be 

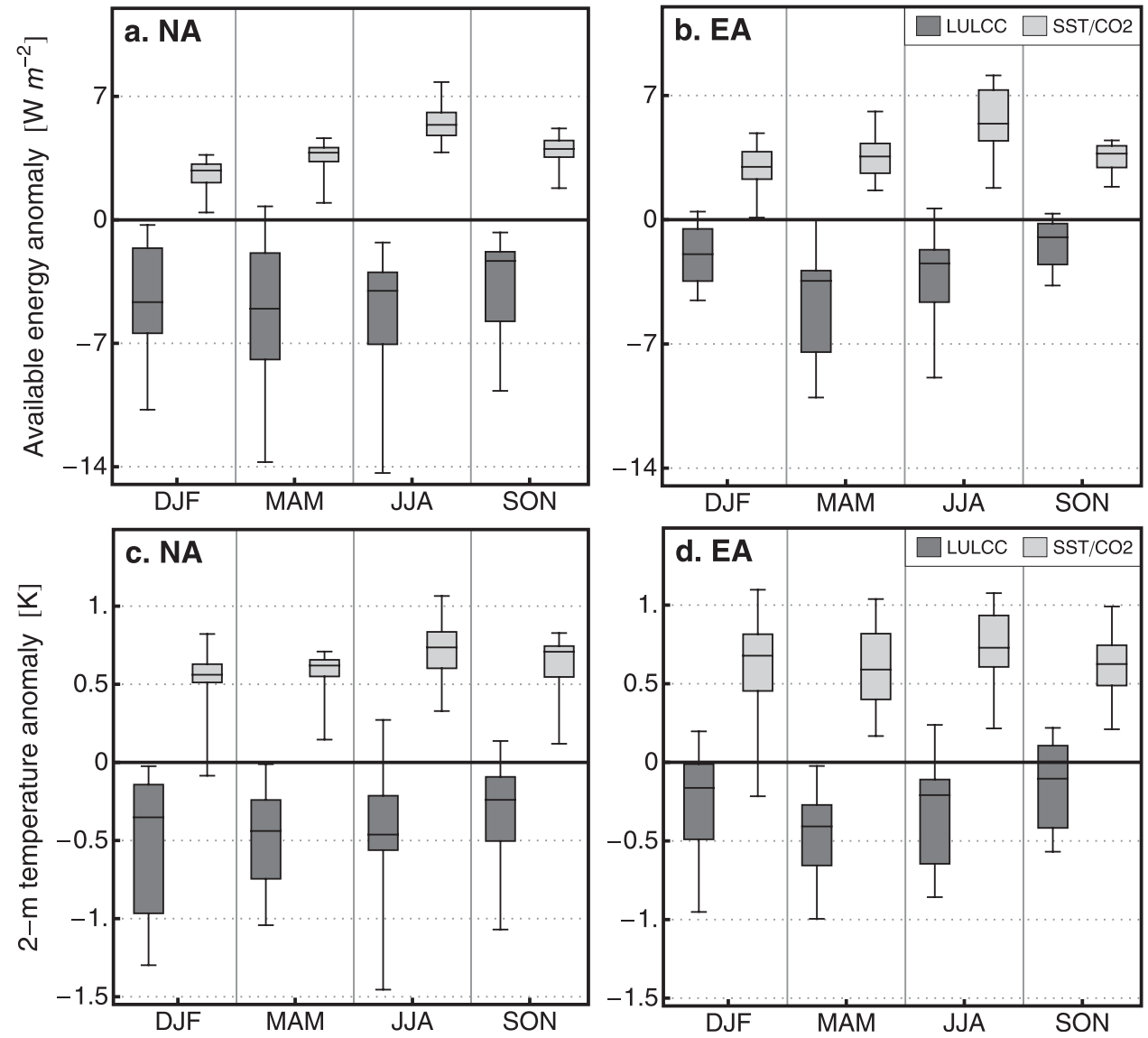

FIG. 3. Box-and-whisker plots of the simulated changes between the PI period and PD in (a),(b) available energy $\left(\mathrm{W} \mathrm{m}^{-2}\right)$ and (c),(d) surface air temperature $\left({ }^{\circ} \mathrm{C}\right)$ for all seasons and for (a),(c) North America and (b),(d) Eurasia. The mean ensemble values of each individual model and each set of experiment (i.e., PD - PIv and PDv - PI for the CO2SST impacts; PD - PDv and PIv - PI for the LULCC impacts) have been used to create this plot. The bottom and top of the box are the 25 th and 75 th percentiles, and the horizontal line within each box is the 50th percentile (the median). The whiskers (straight lines) indicate the ensemble maximum and minimum values.

discussed in section 5. The magnitude of the simulated changes is generally smaller over Eurasia than over North America due to smaller LULCC changes in the former region (see Table 4). The dominant impact of lowered $Q_{A}$ is a quasi-systematic cooling of the land by about $-0.44^{\circ}$ $\pm 0.4^{\circ} \mathrm{C}$ in North America and about $-0.3 \pm 0.3^{\circ} \mathrm{C}$ in Eurasia in all seasons (Figs. 3c,d). The changes in temperature are larger in spring and summer, that is, during the growing season, but the uncertainty is large in DecemberFebruary (DJF), particularly in North America.

There are two remarkable features that can to be highlighted from Fig. 3:

1) In the regions considered, the CO2SST-induced warming (and increase in $Q_{A}$ ) and LULCC-induced cooling (and decrease in $Q_{A}$ ) differ much less than their global mean values. This occurs despite that changes in CO2SST lead to significant mean global annual temperature change (an average over the seven models of $0.432^{\circ} \mathrm{C}$ globally and of $0.625^{\circ} \mathrm{C}$ over land only), while the response to LULCC is negligible at that scale (an average of $-0.019^{\circ} \mathrm{C}$ over the globe and of $-0.069^{\circ} \mathrm{C}$ over land; see Table 5). This emphasizes the global role of $\mathrm{CO}_{2}$ (and resulting surface ocean changes) compared to the regional significance of biogeophysical effects of LULCC. It also points to the importance of not restricting the quantification of climate change to global averages (e.g., the change in mean global annual temperature), since this hides changes of similar importance over some specific (and densely populated) regions. This issue has been addressed thoroughly by Pielke et al. (2002) and Davin et al. (2007).

2) The spread among the models is larger when the models are forced with LULCC than when they are forced with CO2SST. This results from the absence 


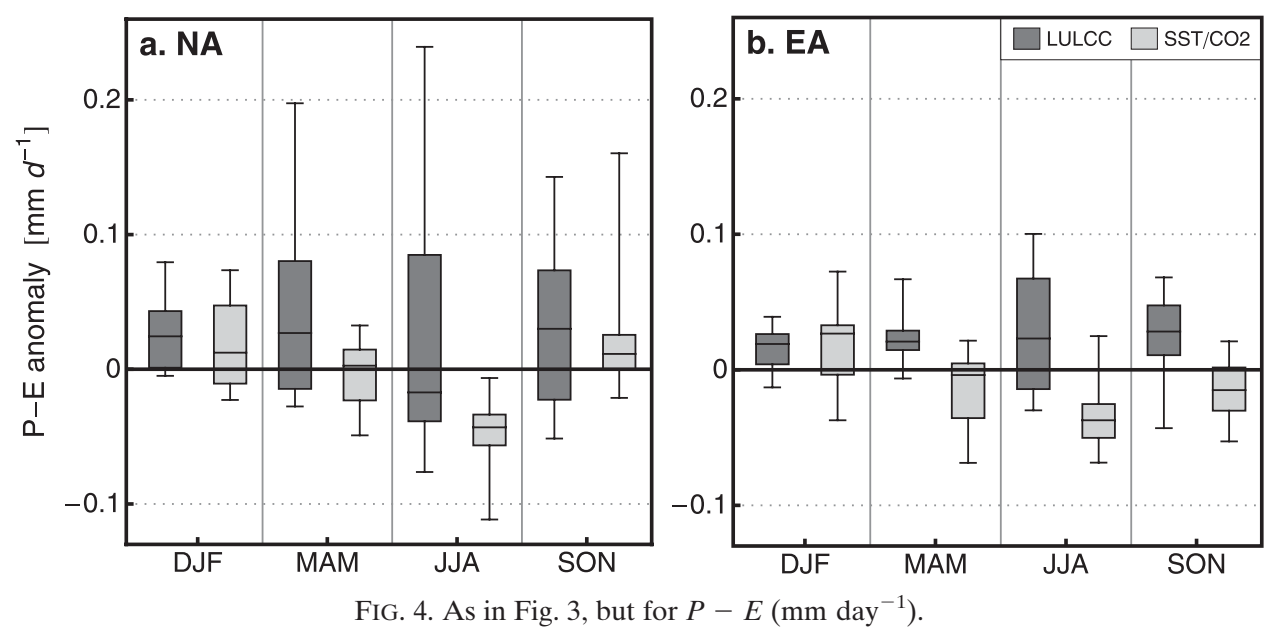

of consistent change among the various models regarding the impact of land cover type on the partitioning of $Q_{A}$ between $Q_{E}$ and $Q_{H}$ (section 6). When the models are forced with changes in CO2SST, it is the incoming total energy provided by the atmosphere to the LSMs that is perturbed and not necessarily the way this energy is subsequently partitioned. The increased incoming energy results in increased $Q_{A}$ that leads to warming in all models, since more than $75 \%$ of it is used to warm up the land. When the models' external forcing is LULCC, it is not the total incoming energy that is perturbed (except potentially via resulting feedbacks), but the way it is partitioned into absorbed and reemitted energy. Not only is this absorbed energy (and thereby $Q_{A}$ ) systematically reduced in all models during all seasons due to increased surface albedo but the fraction of it that is used to warm up the land is also modified by LULCC (see section 6).

In the regions of maximum LULCC changes (i.e., North America and Eurasia), the CO2SST-induced warming is compensated for by the LULCC-induced cooling, resulting in almost no change between the periods. This has strong implications for the interpretation, detection, and attribution of the observed changes between preindustrial times and present day. If the model used to detect and attribute the observed changes to various causes does not include LULCC, then erroneous conclusions may be drawn from the analyzed simulations.

\section{b. Changes in the surface water balance}

The changes in the surface water balance, defined as the difference between rainfall $(P)$ and total evapotranspiration $(E)$ in each model, for each season and each region, shows a distinct seasonal cycle of the simulated anomalies in response to CO2SST. The response to LULCC shows no such cycle (Fig. 4). As a result of LULCC, $P-E$ increases slightly in the majority of models during winter, spring, and fall in response to a small reduction in $E$ and no significant change in $P$. During summertime in North America, more than half of the models show decreased

TABLE 5. Changes in mean annual global 2-m air temperature, together with the mean annual values computed over land only, in all models and the average over the seven models. "LULCC" shows the impact of LULCC between PI times and PD, while "CO2SST" refers to the impact of the combined changes in atmospheric $\mathrm{CO}_{2}$ (and equivalent GHGs) and SST and sea ice.

\begin{tabular}{|c|c|c|c|c|}
\hline \multirow[b]{2}{*}{ Climate/vegetation model } & \multicolumn{2}{|c|}{$\begin{array}{l}\text { Change in annual mean } \\
\text { global 2-m air temperature }\left({ }^{\circ} \mathrm{C}\right)\end{array}$} & \multicolumn{2}{|c|}{$\begin{array}{l}\text { Change in annual mean } 2-\mathrm{m} \text { air } \\
\text { temperature over land only }\left({ }^{\circ} \mathrm{C}\right) \\
\text { (excluding Antarctica) }\end{array}$} \\
\hline & LULCC & $\overline{\text { CO2SST }}$ & LULCC & CO2SST \\
\hline EC-EARTH-TESSEL & -0.042 & 0.511 & -0.13 & 0.65 \\
\hline SPEEDY-LPJmL & -0.056 & —* & -0.1 & - \\
\hline IPSL-ORCHIDEE & -0.005 & 0.48 & -0.011 & 0.55 \\
\hline ARPEGE-ISBA & -0.041 & 0.451 & -0.177 & 0.536 \\
\hline CCAM-CABLE & 0.021 & 0.47 & -0.013 & 0.67 \\
\hline CCSM-CLM & -0.007 & 0.496 & -0.023 & 0.624 \\
\hline ECHAM5-JSBACH & -0.005 & 0.531 & -0.032 & 0.718 \\
\hline Average & -0.019 & 0.432 & -0.069 & 0.625 \\
\hline
\end{tabular}

* SPEEDY-LPJmL did not carry out a CO2SST run. 
SURFACE ALBEDO $[\times 100]$

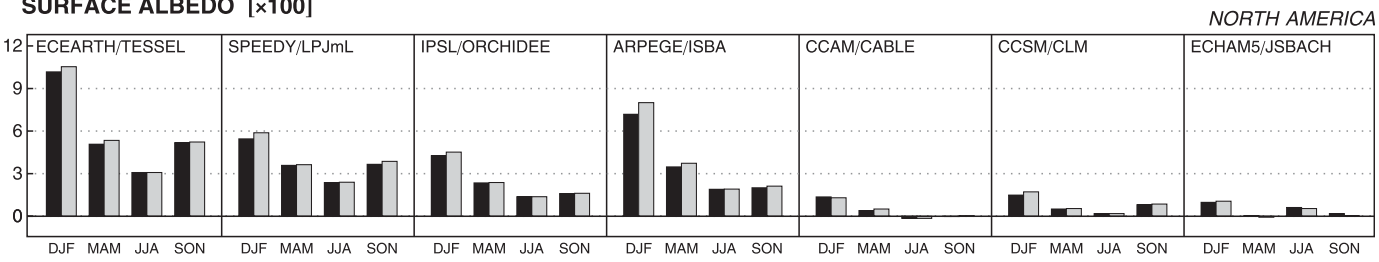

EURASIA

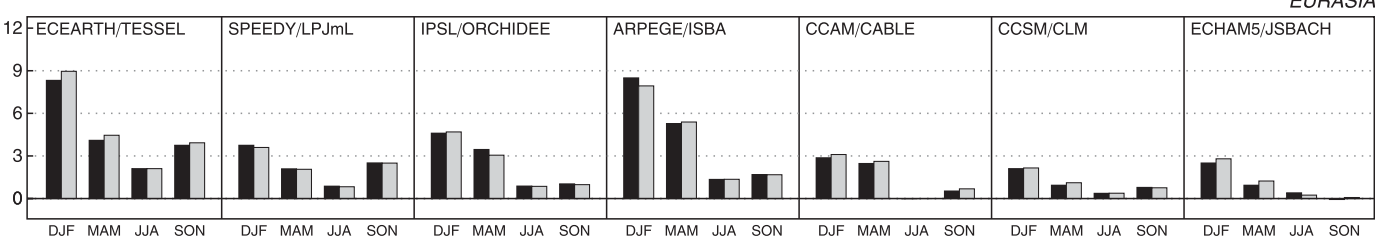

FIG. 5. Seasonal LULCC-induced changes in the simulated surface albedo (\%) between PD and PI times by the models listed at the top of each panel. The shading refer to the differences calculated between the simulations that are forced with PD SSTs, $\mathrm{CO}_{2}$, and GHG (black, simulation PD minus simulation PDv) and PI SSTs, $\mathrm{CO}_{2}$, and GHG (gray, simulation PIv minus simulation PI). Presenting both dark and gray bars demonstrates the robustness of the impacts of LULCC changes, largely independent of the state of the background GHG and surface ocean's temperatures. (top) North America and (bottom) Eurasia. All seasons are plotted from (left) winter (DJF) to (right) fall [September-November (SON)].

$P-E$. However, Fig. 4 shows a very large level of spread between the models, much larger than the spread resulting from the CO2SST forcing. The reason for this increased dispersion (which was also referred to in the previous section) will be discussed in section 6 .

When the models are forced with changes in CO2SST, a summer drying results from a combination of reduced rainfall and increased evapotranspiration. The latter is mainly a response to warmer temperatures (see, e.g., Wetherald and Manabe 2002; Gerten et al. 2007). For the summer season, for a number of models (less than half of them), the changes resulting from CO2SST are opposite of those resulting from LULCC. This again has consequences for detection and attribution efforts, since our results highlight the fundamentally different fingerprint LULCC has on the water availability in comparison to changes in $\mathrm{CO}_{2}$.

\section{Changes in surface properties, fluxes, and temperature}

Changes in LULCC affect many land surface characteristics (e.g., albedo, roughness length, foliage density), some of which affect $Q_{A}$. Changes in these characteristics, and changes in $Q_{A}$, affect the total sum of $Q_{H}$ and $Q_{E}$, and the partitioning of these two fluxes. These changes affect surface temperature, boundary layer profiles of water and heat, and potentially cloud, convection, rainfall, etc. (Betts et al. 1996; Pitman 2003).

\section{a. Resulting changes in land surface characteristics}

In all models, in all seasons, the mean land surface albedo is higher under modern land cover than in preindustrial times (Fig. 5), especially during winter, when snow cover affects some of the temperate regions that have experienced the largest LULCC. The magnitude of the albedo change varies from less than $1 \%$ in winter in some models (e.g., ECHAM5-JSBACH) to about $8 \%$ in others (e.g., SPEEDY-LPJmL, ARPEGE-ISBA, EC-EARTHTESSEL). The spread is quite smaller during summer (from 0.05 to about $3 \%$ at most) and fall, when vegetation foliage is fully developed and snow is not a factor.

In summer (when snow plays no role), the spread in albedo among all but one model is nearly proportional to the scale of deforestation the various models have undergone (Fig. 6). CCAM-CABLE shows a small albedo change despite a significant deforestation. In this version of the model, the parameters used in calculating canopy albedo (Sellers et al. 1992) do not vary as a function of plant functional type, making the model albedo insensitive to changes in the vegetation structure (this has been revised in more recent versions of the model). For the other models, the JJA albedo changes are roughly proportional to the deforestation scale, with an average albedo increase of $7 \%$ for an almost complete forest clearance. This proportionality is quite interesting because it means that even though the LSMs have been developed independently, the albedo's response to deforestation is quite similar from one model to another. It also implies that, to first order, modelers can perform a presimulation test of their implementation of LULCC before running experiments. One could indeed require the change in forest area to be agreed upon between modeling groups, since this largely constrains the resulting change in albedo. In DJF the interactions between vegetation and snow significantly complicate the relationship between the change in forest fraction and albedo (Fig. 6, left panel). 

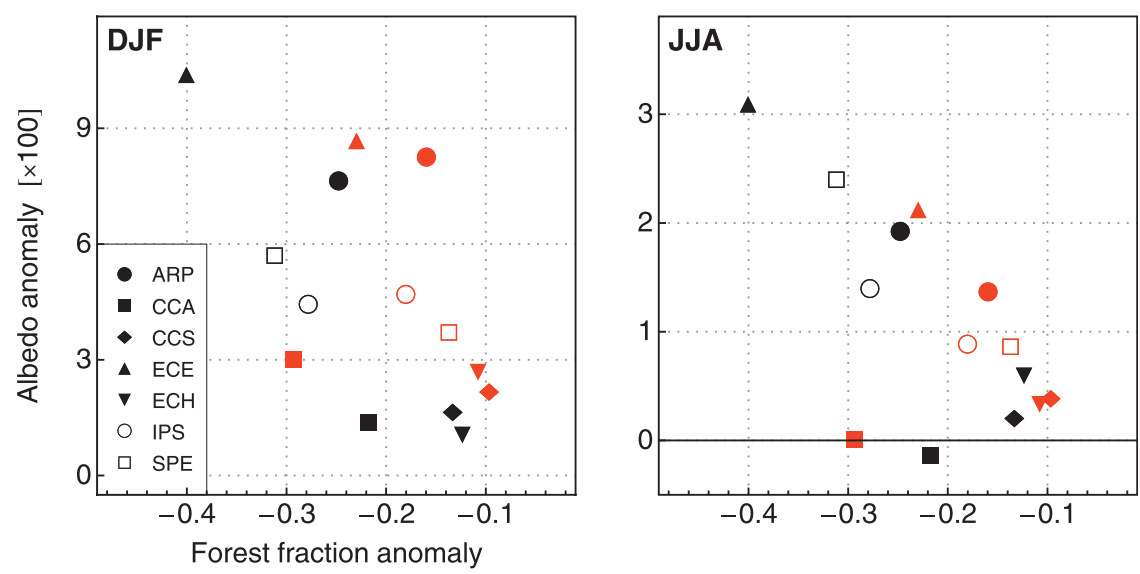

FIG. 6. LULCC-induced changes in the simulated surface albedo (\%) plotted against the changes in forest fraction between PD and PI times. Symbols refer to the various models used (ARP: ARPEGE-ISBA; CCA: CCAM-CABLE; CCS: CSSM-CLM; ECE: EC-EARTHTESSEL; ECH: ECHAM5-JSBACH; IPS: IPSL-ORCHIDEE; SPE: SPEEDY-LPJmL). Red symbols are for Eurasia, while black symbols are for North America. (left) Winter changes (DJF); (right) summer changes (JJA). Albedo values have been computed, for each model, as the mean over not only the various ensemble members but also the two sets of simulations (i.e., PD - PDv and PIv - PI).

The changes in leaf area index (LAI; Fig. 7) are not as homogeneous among the models as the changes in surface albedo. All models show decreased foliage development during wintertime in North America and Eurasia as expected, since forests and grasslands have commonly been replaced by crops, which have negligible foliage development at that time of the year. However, four out of the seven models show at least one season during which the LAI is increased once crops and pasture have replaced forests and grasses (ARPEGEISBA, CCAM-CABLE, ECHAM-JSBACH, IPSLORCHIDEE). The reasons for this increased LAI in spring (for IPSL-ORCHIDEE) or in summer (for ARPEGE-ISBA and ECHAM5-JSBACH) results either from a shift in the seasonal cycle (leaf phenology)—crop leaves in those models do not emerge at the same time as tree leaves, and the length of the growth season is quite shorter for crops than for most other plant types-or from a larger LAI for crops than for grasses (e.g., for ARPEGE-ISBA).

Regarding the relation between the scale of deforestation and the amplitude of albedo changes, there is no such clear link between the deforested fraction and changes in LAI (Fig. 8). Many variables determine the representation of LAI in most models. For example, in IPSL-ORCHIDEE, ECHAM-JSBACH, and SPEEDYLPJmL, LAI is computed for each vegetation type and results from multiple simulated processes (photosynthesis, respiration, allocation) determined by parameters specific to individual plant function types. In all other models, LAI
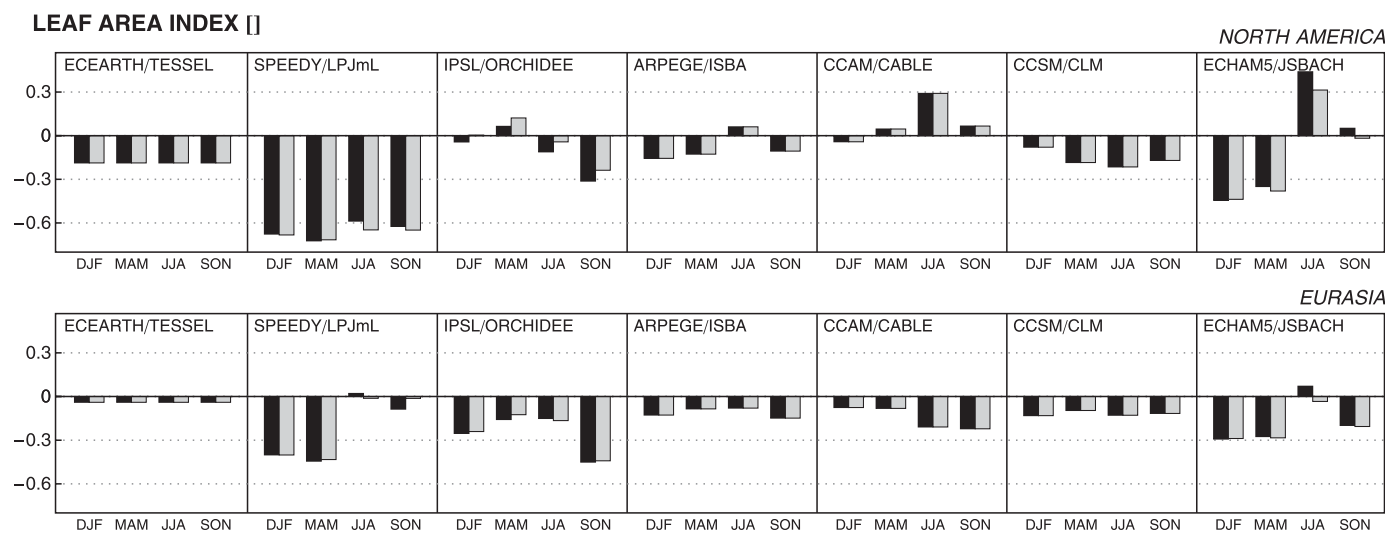

FIG. 7. As in Fig. 5, but for the simulated or imposed changes in LAI. 

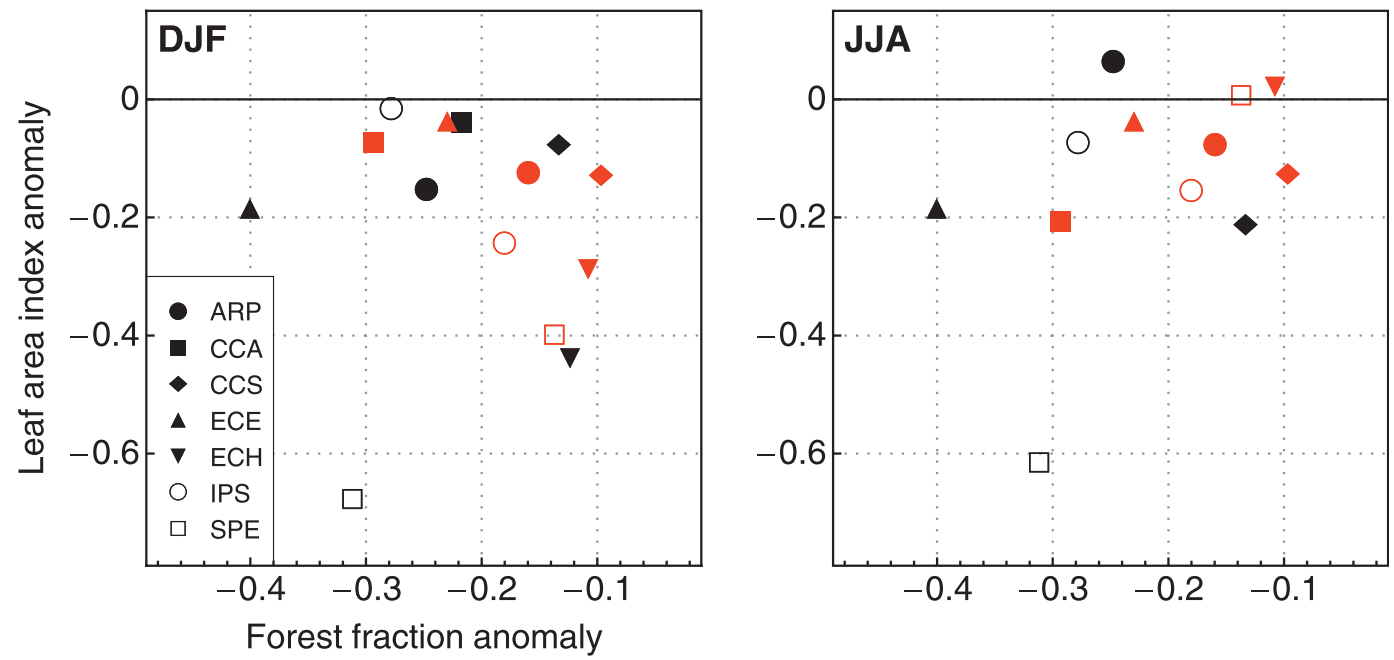

FIG. 8. As in Fig. 6, but for the simulated or imposed changes in LAI.

is prescribed per pixel and per vegetation type and is therefore independent of the potential surface climate change that the climate model may have undergone between preindustrial times and present day.

\section{b. Changes in available energy}

Following the changes in surface albedo, $Q_{A}$ decreases in the temperate regions, for all seasons and all models (Fig. 9). This decrease in $Q_{A}$ is proportional to the albedo change (not shown), and therefore approximately proportional to the scale of deforestation each model has undergone, except for CCAM-CABLE, as discussed in the previous section. In contrast to the albedo change, the changes in $Q_{A}$ are at a maximum during spring and summer for all models when incident solar radiation is highest.

In addition, the LULCC simulations induce a reduced atmospheric longwave radiation emission. This (indirect) effect is led by the changes in the surface energy budget, which result in a reduced heat transferred back into the upper levels and in a lower equilibrium atmospheric temperature (Van der Molen et al. 2011).

Averaged over all models, the decrease in mean annual $Q_{A}$ varies between 1 and more than $10 \mathrm{~W} \mathrm{~m}^{-2}$ (for EC-EARTH-TESSEL) in the northern temperate regions of North America and Eurasia, which represents a change of about $1 \%-10 \%$ compared to the preindustrial simulated values (Fig. 10).

\section{c. Changes in surface heat fluxes (turbulent and thermal radiative)}

The simulated decrease in $Q_{A}$ discussed above is accompanied - for all models, in all seasons and locationsby a systematic decrease (Figs. 11a,c for summer changes)

AVAILABLE ENERGY. Downward LW rad. (black) + net SW rad. (gray) $\left[W \mathrm{~m}^{-2}\right]$
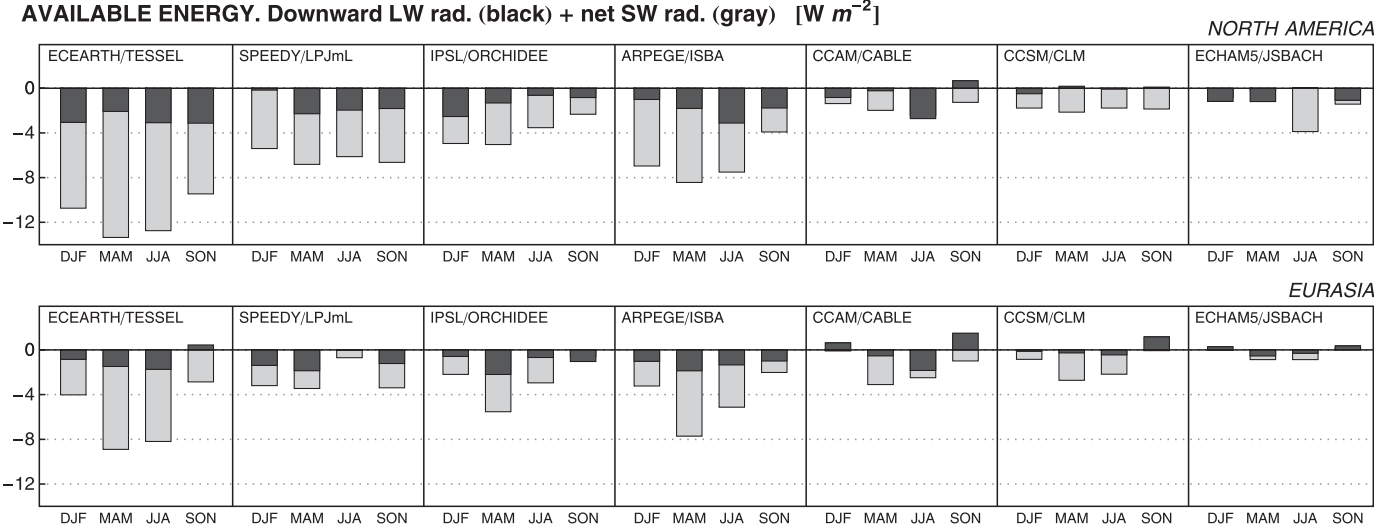

FIG. 9. As in Fig. 5, but for changes in $Q_{A}\left(\mathrm{~W} \mathrm{~m}^{-2}\right)$, separately showing a response in net shortwave (SW) radiation (gray) and downward longwave (LW) radiation (black). 


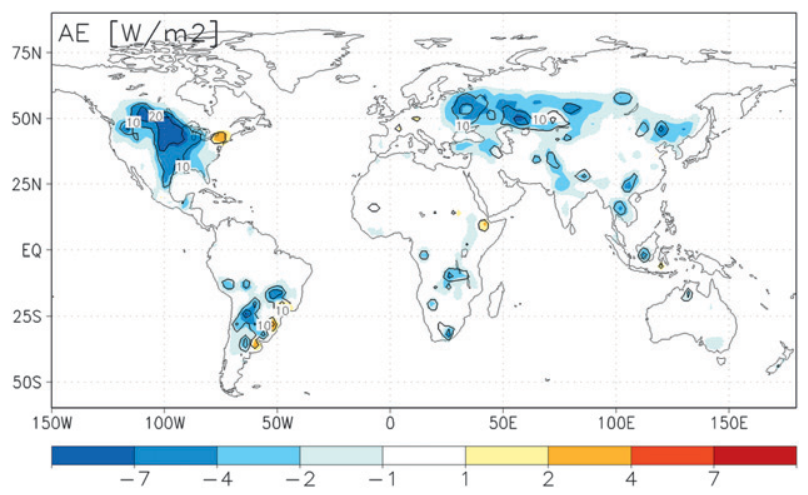

FIG. 10. Mean annual LULCC-induced change in available energy, averaged over all models and all experiments [0.5 (PD $\mathrm{PDv}+\mathrm{PIv}-\mathrm{PI})]$. Shadings refer to the changes in $\mathrm{W} \mathrm{m}^{-2}$, while isolines represent the standard deviation between the models.

in $Q_{T}$. For most models the Northern Hemisphere summer change in turbulent fluxes is smaller than the change in $Q_{A}$. This suggests that the remaining energy decrease has been used to cool down the land, resulting in reduced emitted thermal radiation as illustrated by Figs. 11b,d. For the remaining models: IPSL-ORCHIDEE and CCAMCABLE (as well as SPEEDY-LPJmL for Eurasia), $\Delta Q_{A}$ is larger than $\Delta Q_{T}$. In IPSL-ORCHIDEE, this is compensated for by increased emitted thermal radiation, that is, surface warming, while in CCAM-CABLE (and SPEEDY-LPJmL for Eurasia) the smaller turbulent fluxes are compensated for by an increased heat flux into the ground $\left(Q_{G}\right)$.

Even for the five (four in Eurasia) models that decrease $Q_{T}$ less than $Q_{A}$, the relative change $\left(\Delta Q_{T} / \Delta Q_{A}\right)$ varies from one model to the other. In Northern America it ranges from about $25 \%$ for ARPEGEISBA and ECHAM-JSBACH to more than $50 \%$ for EC-EARTH-TESSEL and CCSM-CLM and to about $100 \%$ for SPEEDY-LPJmL. Moreover, for two out of those five models (EC-EARTH-TESSEL, SPEEDYLPJmL), the simulated change in $Q_{T}$ is larger than what was expected, from the simple assumption that the fraction of energy used for turbulent fluxes is the same for all periods (gray shaded area in Figs. 11a,c). These results suggest that changing land cover and its associated characteristics have led to a change in the functioning of the soil-vegetation-atmosphere in a number of models. In most cases, crops and grasslands are less efficient than trees in transferring energy back to the atmosphere in the form of turbulent fluxes. This is further confirmed by Fig. 12, which shows a systematic decrease in the ratio: $Q_{T} / Q_{A}$ for all seasons and for all models. Interestingly, all models at preindustrial times show rather comparable use of $Q_{A}$ for turbulent fluxes for all seasons, with a maximum use during summertime $(\sim 25 \%)$, followed by spring $(\sim 20 \%)$ and fall $(\sim 12 \%)$, and with minimum use during wintertime $(\sim 5 \%)$. The largest changes in the use of this energy following the imposed LULCC are obtained for EC-EARTH-TESSEL, SPEEDYLPJmL, and IPSL-ORCHIDEE, that is, the models that undergo the largest deforestation rates $(-40 \%,-31 \%$, $-28 \%$ respectively), while the smallest changes are obtained for CCSM-CLM and ECHAM5-JSBACH, which experience the lowest deforestation rates $(13 \%$ and $12 \%$, respectively). Variations among the models can be found in the timing of the maximum change in the $Q_{T} / Q_{A}$ ratio. For two models the maximum reduction of this ratio occurs in summer (IPSL-ORCHIDEE and CCAM-CABLE); for SPEEDY-LPJmL, ARPEGEISBA, and ECHAM5-JSBACH, the maximum changes occur in winter; while for EC-EARTH-TESSEL, it occurs in spring.

The decrease in the $Q_{T} / Q_{A}$ ratio for all models at all seasons suggests that deforestation leads to an increased portion of $Q_{A}$ that is used to warm up the land (reduced long-wave cooling), while the sum of the turbulent fluxes $\left(Q_{H}\right.$ and $\left.Q_{E}\right)$ decreases. This is a common feature shared by all models even though the season of maximum decrease varies from one model to the other. One possible cause is a decrease in the aerodynamic roughness length, which reduces the capacity of the land to exchange energy with the atmosphere via turbulence.

\section{d. Changes in surface temperature}

All models that undergo a change in their forest fraction that is larger than $15 \%^{2}$ simulate cooler ambient air temperature in all seasons (Fig. 13). This results from the simulated decrease in both surface albedo and $Q_{A}$. One exception is IPSL-ORCHIDEE, which simulates a small warming during summer and fall in response to the large decrease in turbulent fluxes that exceeds the decrease in $Q_{A}$, as discussed earlier. CCSMCLM, ECHAM5-JSBACH, and SPEEDY-LPJmL (for Eurasia only) experience the lowest deforestation rates (between 10 and 15\%) and exhibit smaller changes in temperature. Those changes though still tend to be negative.

Our results then tend to point to a rather systematic (and therefore potentially robust) cooling associated with LULCC in the temperate regions, for six out of seven models. The IPSL-ORCHIDEE model shows warming instead of cooling during summer and fall due

\footnotetext{
${ }^{2}$ For example, ARPGE-ISBA, CCAM-CABLE, EC-EARTHTESSEL, IPSL-ORCHIDEE, and SPEEDY-LPJmL in North America.
} 

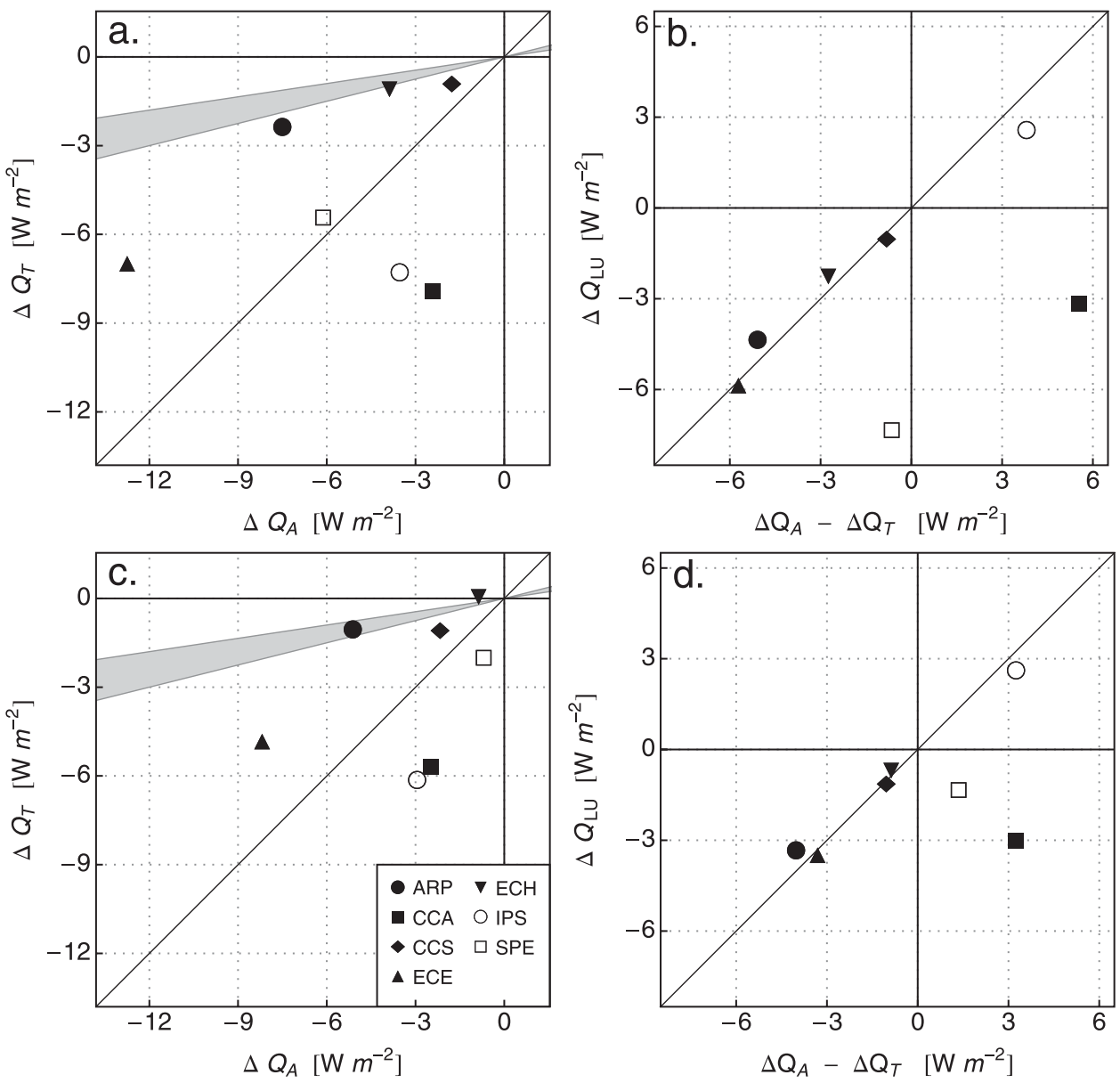

FIG. 11. Mean summer LULCC-induced changes $\left(\mathrm{W} \mathrm{m}^{-2}\right)$ in (a),(c) $Q_{T}$ plotted against the mean summer changes in $Q_{A}$; (b),(d) longwave radiation emitted by the surface $\left(Q_{\mathrm{LU}}\right)$ plotted against the changes in the difference between $Q_{A}$ and $Q_{T}$. (a),(b) North America; (c),(d) Eurasia. Symbols refer to individual models. Plain line in all panels represents the 1:1 regression. Gray shaded area in (left) refers to the changes in $Q_{T}$ that would have occurred if $Q_{T} / Q_{A}$ ratios were the same at PD and PI periods (see section $4 \mathrm{c}$ for discussion).

to 1 ) the very strong subsequent partitioning of $Q_{A}$ into $Q_{H}$ rather than $Q_{E}$ in all periods (see section 5) and 2) the strong sensitivity of $Q_{E}$ to vegetation change through changes in surface parameters (notably, roughness length).

\section{How do LULCC modify the partitioning of available energy in latent and sensible heat fluxes? Is there any consistency among the models?}

The partitioning of turbulent fluxes into $Q_{E}$ and $Q_{H}$ (expressed by the Bowen ratio $\mathrm{BR}=Q_{H} / Q_{E}$ ), and its changes since preindustrial times are shown in Fig. 14. The spread among the models is large, both in terms of its seasonal cycle and its response to deforestation. SPEEDYLPJmL and IPSL-ORCHIDEE tend to maximize BR in all seasons except winter. From March to November, $Q_{H}$ is
1.1-1.5 times larger than $Q_{E}$ for those models, while for CCAM-CABLE, CCSM-CLM, EC-EARTH-TESSEL, and ARPEGE-ISBA, $Q_{H}$ is always smaller than $Q_{E}$ (from 0.39 to 0.71 ). However, this grouping of models does not imply they will similarly respond to deforestation. SPEEDY-LPJmL and IPSL-ORCHIDEE show a consistent decrease in BR in winter and increases in summer and fall, but they show opposite responses in spring. Both CCSM-CLM and EC-EARTH-TESSEL increase the return of energy in the atmosphere in terms of $Q_{E}$ rather than $Q_{H}$, although their forest fraction has strongly diminished. For ARPEGE-ISBA, CCAMCABLE, and ECHAM5-JSBACH, BR decreases marginally in summer, while changes in the other seasons show increases or decreases. There is therefore no consistent pattern among the various models regarding how $Q_{E}$ and $Q_{H}$ change from one season to another. 


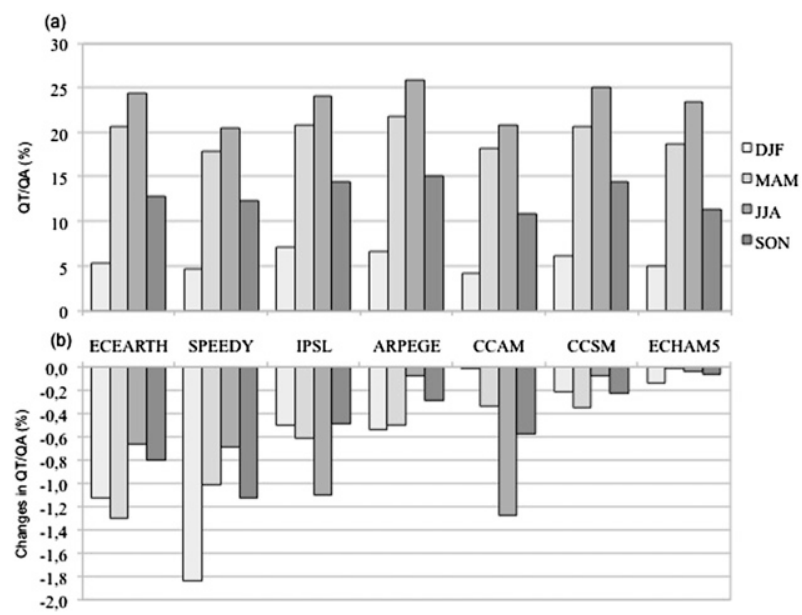

FIG. 12. Mean seasonal values of (a) the fraction of available energy used for turbulent fluxes (i.e., $Q_{T} / Q_{A}$; \%) for each LSM for PI conditions. (b) The LULCC-induced changes in this fraction between PD and PI periods.

Some decrease both fluxes in response to the decrease in $Q_{T}$, others increase $Q_{H}$ and decrease $Q_{E}$ (or vice versa).

Moreover, the reasons why the models differ so considerably vary from model to model. We discuss the reasons for North America, from the results displayed in Fig. 14:

- The seasonal cycle of leaf area index in IPSLORCHIDEE is slightly shifted toward earlier dates (section 5a), which leads to larger values of LAI in spring and smaller values in all other seasons. ORCHIDEE is sensitive to changes in LAI, and $Q_{E}$ is increased in spring (despite the decrease in $Q_{A}$ ) and decreased in all other seasons. The warming of the ambient air in summer and fall results from this significant reduction in $Q_{E}$ that more than compensates the change in $Q_{H}$.
- In June-August (JJA), EC-EARTH mimics the effects of ORCHIDEE in spring: the reduction in $Q_{A}$ gives rise to excessive reductions in $Q_{H}$ and a compensating increase in $Q_{E}$, supported by lower evaporation and soil moisture depletion rates in DJF and MarchMay (MAM). Van der Molen et al. (2011) showed a positive temperature feedback of the surface energy balance in midlatitude deforestation areas, enhancing the albedo-induced cooling by an increased evaporation during boreal summer.

- The changes in CCAM-CABLE are very small. To a large degree, this is related to the small change in $Q_{A}$ energy (Fig. 9), which relates to the use of parameters in the calculation of albedo that do not vary as a function of vegetation type. Thus, a change in vegetation type does not cause a change in albedo and by implication $Q_{A}$, and thus this element of the driver of the impact of LULCC is not captured.

- The increased $Q_{E}$ in CCSM-CLM arises from the partitioning of $Q_{E}$ into transpiration, evaporation of intercepted water, and soil evaporation. For example, summer transpiration generally decreases with the conversion of forest to crop, as does interception. Soil evaporation increases because the decrease in LAI allows more solar radiation to reach the ground. Soils in CCSM-CLM are wet, and the increased radiation produces increased evaporation. Increases in precipitation as a result of land cover change additionally increase $Q_{E}$, especially in regions of North America.

- In SPEEDY-LPJmL, crops have less access to soil water, as their roots are concentrated $(80 \%)$ in the upper soil layer, while trees can have more roots (up to $40 \%$ ) and thus access to water in the lower soil layer. Reductions in roughness length are responsible for more stable atmospheric conditions, which also reduces $Q_{E}$. During winter, the albedo increase is much larger than during summer for most models. The reduction in

2-M TEMPERATURE [K]
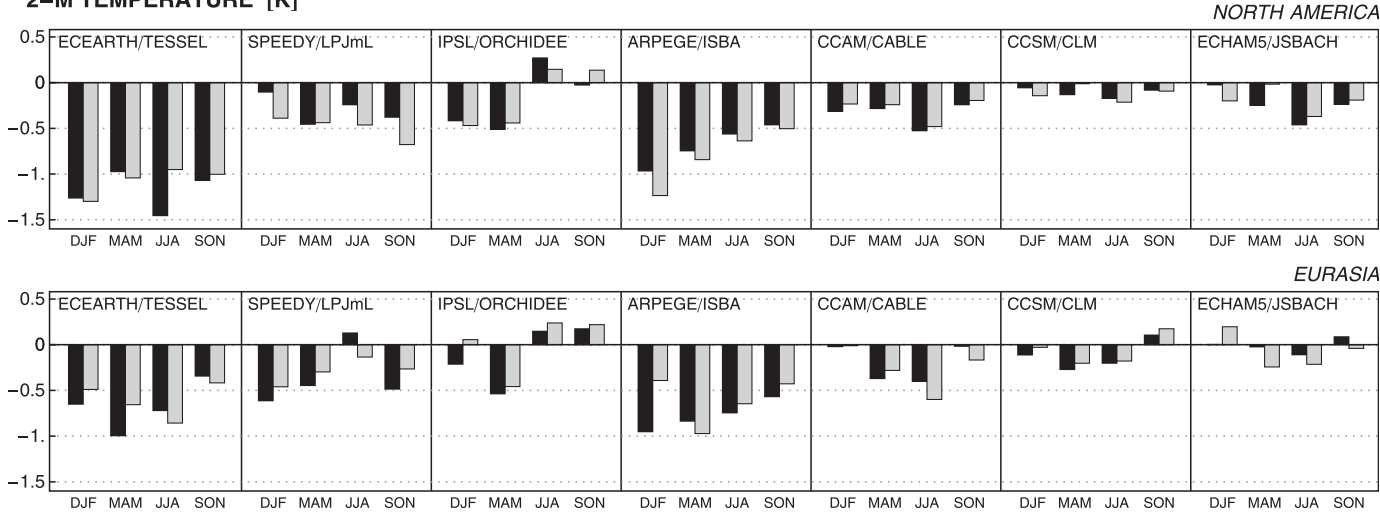

FIG. 13. As for Fig. 5, but for ambient air temperature $\left({ }^{\circ} \mathrm{C}\right)$. 

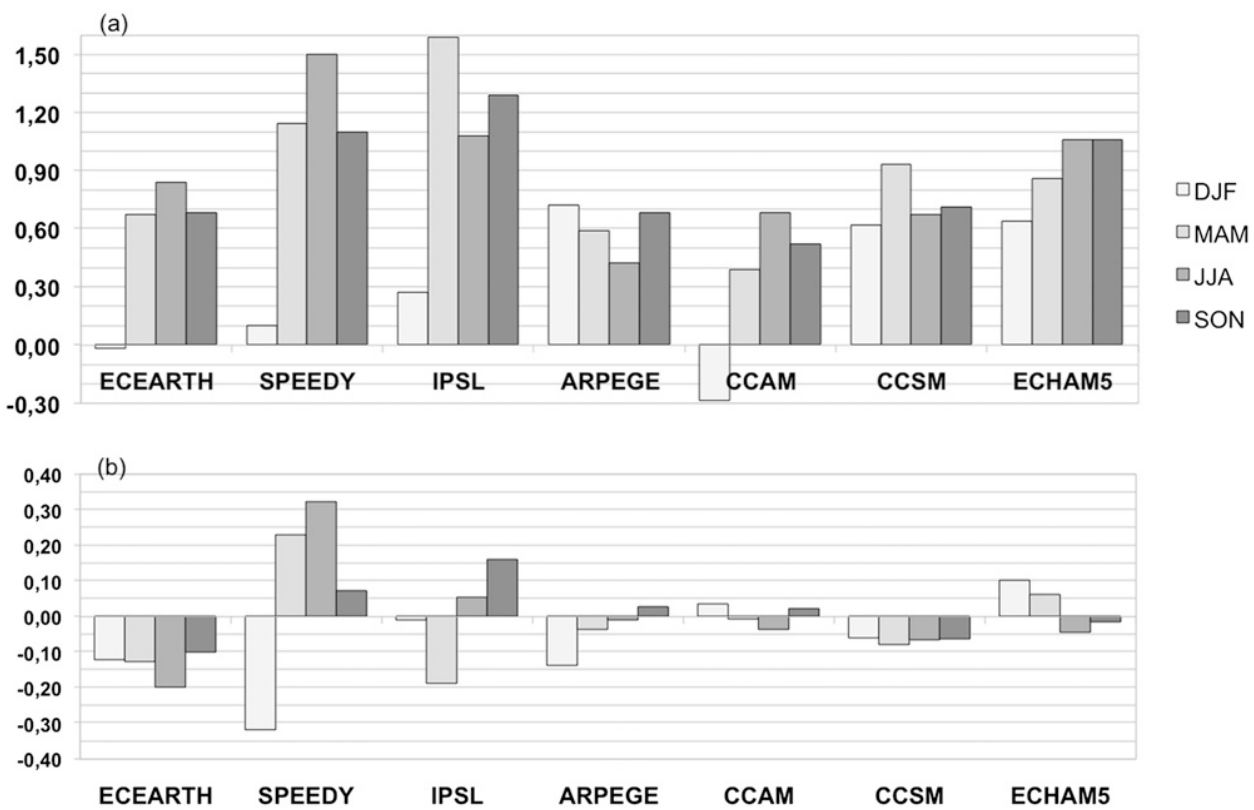

FIG. 14. Mean seasonal values of (a) the BR for each LSM for PI conditions. (b) The LULCC-induced changes in this fraction between PD and PI periods.

turbulent fluxes is more reflected on $Q_{H}$ than on $Q_{E}$, which is always quite small in winter anyway.

- The largest signal with ARPEGE-ISBA comes from the increased snow cover over crops in winter and early spring, reducing the available energy. This reduction leads to a decrease in sensible heat flux because vegetation is mostly inactive. In summer and fall, the higher albedo of crops reduces the available energy and induces a decrease in sensible and latent heat fluxes. The reduction is larger for sensible heat flux in summer, while larger for latent heat flux in the fall. In ARPEGE-ISBA, crops have access to a smaller soil water reservoir than natural vegetation. This limitation is most obvious in the fall, when soil moisture is depleted.

- For ECHAM-JSBACH we see consistent signals in winter, spring, and summer: a decrease (increase) in LAI reduces (increase) the latent heat flux with the converse signal in the sensible heat flux. In fall the behavior is different: the almost unchanged LAI is consistent with almost no change in the latent heat flux but, surprisingly, goes along with a substantial reduction in sensible heat flux, so that maybe nonlocal effects play a role.

\section{Discussion and conclusions}

LUCID undertook a suite of climate model simulations, designed to diagnose and quantify the robust impacts of LULCC on climate between the preindustrial times and the present. Pitman et al. (2009) examined the spatial distribution of summer changes over the whole globe and concluded that there was a lack of consistency among the models. Various reasons for the discrepancies were suggested, without being able to attribute the changes to one or the other at that stage. This paper provides the detailed analysis of the LUCID results to identify the reasons for the discrepancies identified by Pitman et al. (2009).

The large spread of our model results both in terms of preindustrial and present-day values of latent and sensible heat fluxes, and their changes under deforestation confirm that the uncertainty in the $Q_{E}$ response is a key uncertainty in the LULCC forcing at temperate latitudes (Bonan 2008). Our results show that it is not only the change in $Q_{E}$ that matters but also (and probably mainly) how each individual model calculates the seasonally and surface-type-dependent Bowen ratio.

The model spread is quite surprising, given that many of the LSMs have undergone exhaustive validation of their fluxes via offline evaluation studies. However, there are a series of profound limitations in the ways LSMs are usually evaluated and intercompared. These include the following:

1) The evaluation of LSMs tends to be limited in scope, not always objective, relative to a previous version of a model (as distinct to the information content in the observed data), and rarely relative to a benchmark (Abramowitz 2005; Abramowitz et al. 2008). 
2) Almost all LSM evaluation is uncoupled from an atmosphere (offline); this is necessary but insufficient to establish the utility of a model, because the forcing of the atmosphere is very strong and might overshadow some differences in the behavior of the models.

3) Almost all LSM evaluation has been focused on whether the mean state, or diurnal cycle, or seasonal cycle can be captured. Again, this is necessary but insufficient. Rarely is the land surface models' ability to simulate the impact, feedbacks, and associated responses to a perturbation (via elevated radiative forcing, LULCC, a severe rainfall anomaly, a drought, a heat wave, etc.) explored. However, LSMs must be able to simulate these kinds of phenomena to provide climate models the land surface influence required in climate modeling and climate projection.

Our finding therefore suggests that offline evaluation of LSMs is necessary but insufficient and should be complemented by the evaluation of the same models at least coupled to an atmospheric column. Further, an evaluation of a LSM's capacity to capture changes, as distinct from a mean state, has emerged as a priority.

The more in-depth analysis presented in this paper, compared to Pitman et al. (2009), suggests a number of robust common features shared by all models, including the following:

- LULCC leads to a systematic increase in surface albedo in all seasons. For most models, this increase is proportional to the amount of deforestation imposed on the individual models. This proportionality implies that while the LSMs have been developed independently, the models respond quite similarly to LULCC in terms of albedo ( $7 \%$ for a full transition from forest to crop/grassland).

- This larger surface albedo causes a decrease in $Q_{A}$ (computed as the sum of absorbed solar energy and incident atmospheric infrared radiation); $Q_{A}$ decreases everywhere in the temperate regions, in all seasons and for all models. The decrease in $Q_{A}$ is proportional to the amount of deforestation imposed on a given model.

- The simulated decrease in $Q_{A}$ is accompanied, for all models, in all seasons and locations, by a systematic decrease in the sum of $Q_{E}$ and $Q_{H}$.

- All models show a similar seasonal cycle in the amount of $Q_{A}$ being used for turbulent fluxes (i.e., similar $\left.Q_{T} / Q_{A}\right)$. This ratio is always decreased in response to LULCC in all seasons, but this decrease varies across the model ensemble. The mean annual decrease is proportional to the intensity of LULCC.

- In most cases, crops and grasslands are less efficient than trees in transferring energy to the atmosphere in the form of turbulent fluxes due to a lower aerodynamic roughness length.

These common features and their dependence on the amount of LULCC prescribed in each model suggest that, for an agreed amount of deforestation that occurred over specific periods, the dispersion among the models will be significantly smaller.

However, some persistent disparities remain. First, there is no consistency in how $Q_{T}$ is partitioned between $Q_{E}$ and $Q_{H}$ throughout the annual cycle. Second, there is no consistency in the seasonal response of $Q_{H}$ and $Q_{E}$ to LULCC. In some LSMs, deforestation leads to a decrease in both fluxes in response to the decrease in $Q_{A}$ and $Q_{T}$, while in others $Q_{H}$ increases and $Q_{E}$ decreases (or vice versa). This is dependent on how these processes are represented in each LSM. We are not able to attribute these differences to the many parameterization variations. However, our conclusions do point to an urgent need to revisit the way LSMs are evaluated if we are to resolve why they disagree on the impact of LULCC. One significant problem we are facing is that LSMs are generally evaluated offline, forced with prescribed atmospheric forcing. Our results suggest that this is necessary but insufficient. Evaluation of LSMs has to account for atmospheric feedbacks (e.g., Santanello et al. 2009). An evaluation framework should then be completed by series of analyses that determine how well LSMs capture the contrasting dynamic properties of various vegetation types, which are relevant for biosphere-atmosphere interactions (e.g., water use efficiency, dynamics of evaporative fraction, effective temperature sensitivity of carbon balance).

Increased concentration of greenhouse gases in the atmosphere, and the subsequent changes in sea surface temperatures and sea ice extent, are often used as the main drivers of climate change also over land. Our results suggest that such an assumption leads to erroneous conclusions regarding the land surface impacts of climate change in regions where LULCC has been significant. LULCC affects a number of variables to a similar magnitude, but of opposite sign, in increasing greenhouse gas concentrations. LULCC therefore has the potential to mask a regional warming signal, with the resulting risk that detection and attribution studies may miss a clear greenhouse signal or misattribute a greenhouse signal if LULCC is poorly accounted for. Detection and attribution is a complex process that is beyond the scope of this paper (see, e.g., Stott et al. 2010). However, our results suggest that including LULCC could improve the regional-scale detection of the impacts of specific forcings by ensuring that land cover's contribution to any regional changes is appropriately represented. LULCC will suppress the impacts of, for example, increasing 
$\mathrm{CO}_{2}$ in some regions that cool due to land cover change and amplify the impacts of increasing $\mathrm{CO}_{2}$ in regions that warm due to land cover change. In the former case, there is a risk of missing the detection of a $\mathrm{CO}_{2}$ signal, while in the latter there is a risk of a false-positive detection of a $\mathrm{CO}_{2}$ signal. Aerosols, which typically cool, particularly strongly at regional scales, are an additional forcing that might be masked by the misrepresentation of LULCC.

Our findings argue for the inclusion of LULCC in climate projections, as now in process for the CMIP5 simulations (e.g., Arora et al. 2011). However, we have also shown that the differences among the seven models' response to LULCC is larger than the differences that results from the change in CO2SST. Since LULCC is implemented in most CMIP5 models, we expect a larger divergence among climate models in comparison to earlier efforts over regions of intense LULCC, coincident with dense human populations. This problem will only be resolved via a more systematic effort within the climate modeling and land surface modeling communities, starting with a coordinated evaluation of how to represent LULCC, how well models capture the impacts of LULCC in both offline and coupled simulations.

Acknowledgments. The authors gratefully acknowledge the inspiring discussions, input and collaboration among the participants of LULCC initiative, IGBP second synthesis topic on "Land-Use-induced Land-Cover Changes and the functioning of the Earth System."

\section{REFERENCES}

Abramowitz, G., 2005: Towards a benchmark for land surface models. Geophys. Res. Lett., 32, L22702, doi:10.1029/ 2005 GL024419.

_- R. Leuning, M. Clark, and A. Pitman, 2008: Evaluating the performance of land surface models. J. Climate, 21, 5468-5481.

Arneth, A., and Coauthors, 2010: Terrestrial biogeochemical feedbacks in the climate system. Nat. Geosci., 3, 525-532, doi:10.1038/ngeo905.

Arora, V. K., and Coauthors, 2011: Carbon emission limits required to satisfy future representative concentration pathways of greenhouse gases. Geophys. Res. Lett., 38, L05805, doi:10.1029/2010GL046270.

Betts, A. K., J. H. Ball, A. C. M. Beljaars, M. J. Miller, and P. A Viterbo, 1996: The land surface-atmosphere interaction: A review based on observational and global modeling perspectives. J. Geophys. Res., 101, 7209-7225.

Bonan, G. B., 1997: Effects of land use on the climate of the United States. Climatic Change, 37, 449-486.

, 2008: Forests and climate change: Forcings, feedbacks, and the climate benefits of forests. Science, 320, 1444-1449, doi:10.1126/science.1155121.

Bondeau, A., and Coauthors, 2007: Modelling the role of agriculture for the 20th century global terrestrial carbon balance. Global Change Biol., 13, 679-706.
Collins, W. D., and Coauthors, 2006: The Community Climate System Model Version 3 (CCSM3). J. Climate, 19, 2122-2143.

Davin, E. L., and N. de Noblet-Ducoudré, 2010: Climatic impact of global-scale deforestation: Radiative versus nonradiative processes. J. Climate, 23, 97-112.

,-- , and P. Friedlingstein, 2007: Impact of land cover change on surface climate: Relevance of the radiative forcing concept. Geophys. Res. Lett., 34, L13702, doi:10.1029/2007GL029678.

DeFries, R. S., and Coauthors, 1995: Mapping the land surface for global atmosphere-biosphere models: Toward continuous distributions of vegetation's functional properties. J. Geophys. Res., 100, 20 867-20 882.

Denman, K. L., and Coauthors, 2007: Couplings between changes in the climate system and biogeochemistry. Climate Change 2007: The Physical Science Basis, S. D. Solomon et al., Eds., Cambridge University Press, 499-588.

Deo, R. C., J. I. Syktus, C. A. McAlpine, P. J. Lawrence, H. A. McGowan, and S. R. Phinn, 2009: Impact of historical land cover change on daily indices of climate extremes including droughts in eastern Australia. Geophys. Res. Lett., 36, L08705, doi:10.1029/2009GL037666.

Fall, S., D. Niyogi, A. Gluhovsky, R. A. Pielke Sr., E. Kalnay, and G. Rochon, 2010a: Impacts of land use land cover on temperature trends over the continental United States: Assessment using the North American Regional Reanalysis. Int. J. Climatol., 30, 1980-1993.

Findell, K. L., E. Shevliakova, P. C. D. Milly, and R. J. Stouffer, 2007: Modeled impact of anthropogenic land cover change on climate. J. Climate, 20, 3621-3634.

— A. J. Pitman, M. H. England, and P. Pegion, 2009: Regional and global impacts of land cover change and sea surface temperature anomalies. J. Climate, 22, 3248-3269.

Forster, P. M., and Coauthors, 2007: Changes in atmospheric constituents and in radiative forcing. Climate Change 2007: The Physical Science Basis, S. Solomon et al., Eds., Cambridge University Press, 129-234.

Gallo, K. P., T. W. Owen, D. R. Easterling, and P. F. Jamason, 1999: Temperature trends of the U.S. Historical Climatology Network based on satellite designated land use/land cover. J. Climate, 12, 1344-1348.

Gedney, N., and P. J. Valdes, 2000: The effect of Amazonian deforestation on the Northern Hemisphere circulation and climate. Geophys. Res. Lett., 27, 12 753-12 758.

Gerten, D., S. Schaphoff, and W. Lucht, 2007: Potential future changes in water limitations of the terrestrial biosphere. Climatic Change, 80, 277-299, doi:10.1007/s10584-0069104-8.

Hale, R. C., K. P. Gallo, T. W. Owen, and T. R. Loveland, 2006: Land use/land cover change effects on temperature trends at U.S. Climate Normals stations. Geophys. Res. Lett., 33, L11703, doi:10.1029/2006GL026358.

Henderson-Sellers, A., R. E. Dickinson, T. B. Durbidge, P. J. Kennedy, K. McGuffie, and A. J. Pitman, 1993: Tropical deforestation: Modeling local- to regional-scale climate change. J. Geophys. Res., 98, 7289-7315.

Hurtt, G. C., S. Frolking, M. G. Fearon, B. Moore III, E. Shevliakova, S. Malyshev, S. W. Pacala, and R. A. Houghton, 2006: The underpinnings of land-use history: Three centuries of global gridded land-use transitions, wood harvest activity, and resulting secondary lands. Global Change Biol., 12, 1208 1229

and Coauthors, 2011: Harmonization of land-use scenarios for the period 1500-2100: 600 years of global gridded annual 
land-use transitions, wood harvest, and resulting secondary lands. Climatic Change, 109, 117-161, doi:10.1007/s10584011-0153-2.

Kaplan, J. O., K. M. Krumhardt, E. C. Ellis, W. F. Ruddiman, C. Lemmen, and K. Klein Goldewijk, 2011: Holocene carbon emissions as a result of anthropogenic land cover change. Holocene, 21, 775-791, doi:10.1177/0959683610386983.

Klein Goldewijk, K., 2001: Estimating global land use change over the past 300 years: The HYDE database. Global Biogeochem. Cycles, 15, 417-433.

—- A. Beusen, G. van Drecht, and M. de Vos, 2011: The HYDE 3.1 spatially explicit database of human-induced global landuse change over the past 12,000 years. Global Ecol. Biogeogr., 20, 73-86, doi:10.1111/j.1466-8238.2010.00587.x.

Krinner, G., and Coauthors, 2005: A dynamical global vegetation model for studies of the coupled atmosphere-biosphere system. Global Biogeochem. Cycles, 19, GB1015, doi:10.1029/ 2003 GB002199.

Lawrence, P. J., and T. N. Chase, 2010: Investigating the climate impacts of global land cover change in the Community Climate System Model. Int. J. Climatol., 30, 2066-2087.

Lobell, D. B., and C. Bonfils, 2008: The effect of irrigation on regional temperatures: A spatial and temporal analysis of trends in California, 1934-2002. J. Climate, 21, 2064 2071.

Loveland, T. R., B. C. Reed, J. F. Brown, D. O. Ohlen, Z. Zhu, L. Yang, and J. W. Merchant, 2000: Development of a global land cover characteristics database and IGBP DISCover from $1 \mathrm{~km}$ AVHRR data. Int. J. Remote Sens., 21, 13031330 .

Mahmood, R., K. G. Hubbard, R. D. Leeper, and S. A. Foster, 2008: Increase in near-surface atmospheric moisture content due to land use changes: Evidence from the observed dewpoint temperature data. Mon. Wea. Rev., 136, 15541561.

Marti, O., and Coauthors, 2010: Key features of the IPSL ocean atmosphere model and its sensitivity to atmospheric resolution. Climate Dyn., 34, 1-26, doi:10.1007/s00382-0090640-6.

Masson, V., J.-L. Champeaux, F. Chauvin, C. Meriguet, and R. Lacaze, 2003: A global database of land surface parameters at $1-\mathrm{km}$ resolution in meteorological and climate models. J. Climate, 16, 1261-1282.

McCarthy, M. P., M. J. Best, and R. A. Betts, 2010: Climate change in cities due to global warming and urban effects. Geophys. Res. Lett., 37, L09705, doi:10.1029/2010GL042845.

McGregor, J. L., and M. R. Dix, 2008: An updated description of the Conformal-Cubic Atmospheric Model. High Resolution Numerical Modelling of the Atmosphere and Ocean, K. Hamilton and W. Ohfuchi, Eds., Springer, 51-76.

Oleson, K. W., G. B. Bonan, S. Levis, and M. Vertenstein, 2004: Effects of land use change on North American climate: Impact of surface datasets and model biogeophysics. Climate Dyn., 23, $117-132$

, and Coauthors, 2008: Improvements to the Community Land Model and their impact on the hydrological cycle. J. Geophys. Res., 113, G01021, doi:10.1029/2007JG000563.

Pielke, R. A., Sr., G. Marland, R. A. Betts, T. N. Chase, J. L. Eastman, J. O. Niles, D. D. S. Niyogi, and S. W. Running, 2002: The influence of land-use change and landscape dynamics on the climate system: Relevance to climate-change policy beyond the radiative effect of greenhouse gases. Philos. Trans. Roy. Soc. London, A360, 1705-1719.
Pitman, A. J., 2003: The evolution of, and revolution in, land surface schemes designed for climate models. Int. J. Climatol., 23, 479-510.

— , and Coauthors, 2009: Uncertainties in climate responses to past land cover change: First results from the LUCID intercomparison study. Geophys. Res. Lett., 36, L14814, doi:10.1029/2009GL039076.

Pongratz, J., C. H. Reick, T. Raddatz, and M. Claussen, 2008: A reconstruction of global agricultural areas and land cover for the last millennium. Global Biogeochem. Cycles, 22, GB3018, doi:10.1029/2007GB003153.

Raddatz, T. J., and Coauthors, 2007: Will the tropical land biosphere dominate the climate-carbon cycle feedback during the twenty-first century? Climate Dyn., 29, 565-574, doi:10.1007/ s00382-007-0247-8.

Ramankutty, N., and J. A. Foley, 1999: Estimating historical changes in global land cover: Croplands from 1700 to 1992. Global Biogeochem. Cycles, 13, 997-1027.

Roeckner, E., and Coauthors, 2006: Sensitivity of simulated climate to horizontal and vertical resolution in the ECHAM5 atmosphere model. J. Climate, 19, 3771-3791.

Salas-Mélia, D., and Coauthors, cited 2005: Description and validation of the CNRM-CM3 global coupled climate model. [Available online at http://www.cnrm.meteo.fr/scenario2004/ paper_cm3.pdf.]

Santanello, J. A., C. D. Peters-Lidard, S. V. Kumar, C. Alonge, and W.-K. Tao, 2009: A modeling and observational framework for diagnosing local land-atmosphere coupling on diurnal time scales. J. Hydrometeor., 10, 577-599.

Sellers, P. J., J. A. Berry, G. J. Collatz, C. B. Field, and F. G. Hall, 1992: Canopy reflectance, photosynthesis, and transpiration. III. A reanalysis using improved leaf models and a new canopy integration scheme. Remote Sens. Environ., 42, 187216.

Seneviratne, S. I., T. Corti, E. L. Davin, M. Hirschi, E. B. Jaeger, I. Lehner, B. Orlowsky, and A. J. Teuling, 2010: Investigating soil moisture-climate interactions in a changing climate: A review. Earth Sci. Rev., 99, 125-161.

Stott, P. A., N. P. Gillett, G. C. Hegerl, D. J. Karoly, D. A. Stone, X. Zhang, and F. Zwiers, 2010: Detection and attribution of climate change: A regional perspective. Wiley Interdiscip. Rev.: Climate Change, 1, 192-211, doi:10.1002/wcc.34.

Strengers, B. J., and Coauthors, 2010: Assessing 20th century climate-vegetation feedbacks of land-use change and natural vegetation dynamics in a fully coupled vegetationclimate model. Int. J. Climatol., 30, 2055-2065, doi:10.1002/ joc. 2132 .

Teuling, A. J., and Coauthors, 2010: Contrasting response of European forest and grassland energy exchange to heatwaves. Nat. Geosci., 3, 722-727, doi:10.1038/ngeo950.

Van den Hurk, B. J. J. M., P. Viterbo, A. C. M. Beljaars, and A. K. Betts, 2000: Offline validation of the ERA40 surface scheme. ECMWF Tech. Memo. 295, 42 pp. [Available online at http:// www.knmi.nl/publications/fulltexts/tm295.pdf.]

Van der Molen, M. K., B. J. J. M. van den Hurk, and W. Hazeleger, 2011: A dampened land use change climate response towards the tropics. Climate Dyn., 37, 2035-2043, doi:10.1007/s00382011-1018-0.

Voldoire, A., 2006: Quantifying the impact of future land-use changes against increases in GHG concentrations. Geophys. Res. Lett., 33, L04701, doi:10.1029/2005GL024354.

Wang, Y. P., D. Baldocchi, R. Leuning, E. Falge, and T. Vesala, 2007: Estimating parameters in a land-surface model by 
applying nonlinear inversion to eddy covariance flux measurements from eight FLUXNET sites. Global Change Biol., 13, 652-670, doi:10.1111/j.1365-2486.2006.01225.x.

Werth, D., and R. Avissar, 2002: The local and global effects of Amazon deforestation. J. Geophys. Res., 107, 8087, doi:10.1029/ 2001JD000717.

Wetherald, R. T., and S. Manabe, 2002: Simulation of hydrologic changes associated with global warming. J. Geophys. Res., 107, 4379, doi:10.1029/2001JD001195.

Williams, M., 2003: Deforesting the Earth: From Prehistory to Global Crisis. University of Chicago Press, 689 pp.
Zhang, H., A. Henderson-Sellers, and K. McGuffie, 1996: Impacts of tropical deforestation. Part I: Process analysis of local climatic change. J. Climate, 9, 1497-1517.

Zhao, M., and A. J. Pitman, 2002: The impact of land cover change and increasing carbon dioxide on the extreme and frequency of maximum temperature and convective precipitation. Geophys. Res. Lett., 29, 1078, doi:10.1029/2001GL013476.

Zhou, L., R. E. Dickinson, Y. Tian, J. Fang, Q. Li, R. K. Kaufman, C. J. Tucker, and R. B. Myneni, 2004: Evidence for a significant urbanization effect on climate in China. Proc. Natl. Acad. Sci. USA, 101, 9540-9544. 